\title{
"Que digan lo que saben y cómo es que lo saben..." Un pedido de información sobre un martirio en las fronteras del Gran Chaco (1639-1640)
}

"Let them say what they know and how they know it..." A request for information on a martyrdom in the frontier of the Gran Chaco (1639-1640)

\section{René Osvaldo Geres}

\section{OpenEdition}

\section{Journals}

\section{Edición electrónica}

URL: http://journals.openedition.org/corpusarchivos/354

DOI: 10.4000/corpusarchivos.354

ISSN: $1853-8037$

Editor

Diego Escolar

\section{Referencia electrónica}

René Osvaldo Geres, " "Que digan lo que saben y cómo es que lo saben..." Un pedido de información sobre un martirio en las fronteras del Gran Chaco (1639-1640) », Corpus [En línea], Vol 3, No 1 | 2013, Publicado el 15 junio 2013, consultado el 20 abril 2019. URL : http://journals.openedition.org/ corpusarchivos/354; DOI : 10.4000/corpusarchivos.354

Este documento fue generado automáticamente el 20 abril 2019. 


\title{
"Que digan lo que saben y cómo es que lo saben..." Un pedido de información sobre un martirio en las fronteras del Gran Chaco (1639-1640)
}

\author{
"Let them say what they know and how they know it..." A request for \\ information on a martyrdom in the frontier of the Gran Chaco (1639-1640)
}

René Osvaldo Geres

\section{NOTA DEL EDITOR}

Fecha de recepción del original: 10-14-2013

Fecha de aceptación para publicación: 14-05-2013

\section{Introducción}

1 Las fronteras del Obispado del Tucumán conformaban hacia la primera mitad del siglo XVII un amplio territorio en donde la cuestión de la sujeción y conversión de los indígenas fueron problemas de primera hora en la agenda de las autoridades de gobierno ${ }^{1}$ . Felipe de Albornoz llegaría a escribir al Rey en 1634 que "mientras los señores obispos no ayudaren mucho por la suya no puede esto tener el devido remedio porque ellos quieren ser algunos mas Dueños de los yndios que los propios encomenderos"2. En efecto, la situación no era fácil para los centenares de indígenas que formaban parte de los pueblos de indios ubicados en los márgenes de las jurisdicciones. Hacia mediados del siglo XVII las fronteras de Salta y Jujuy ingresaron en un proceso de institucionalización militar y religiosa que implicó, además de la explotación de los pastizales para el engorde de ganado y sembradíos, la instalación de fuertes, capillas y reducciones (Chaile, 2011, p. 50). 
En el Valle de Jujuy es posible observar así un proceso particular, con la creación de reducciones de indios depositadas a cargo de españoles o bajo control de algunos pocos efectivos militares (Sánchez y Sica, 1997, p. 60). Estos pueblos, lejos de permanecer aislados de los grupos indígenas no reducidos, mantuvieron a lo largo del siglo XVII contactos de diversa índole, desde enfrentamientos hasta prácticas de intercambio de bienes materiales y celebraciones rituales ${ }^{3}$.

2 El documento que presentamos refleja parte de la situación de esta frontera en la primera mitad del siglo XVII. El espacio en el que nos situaremos, surcado por los ríos Perico y Siancas, formaba parte de la frontera al este de Humahuaca y de los umbrales del Gran Chaco, un complejo fronterizo en donde la circulación e intercambios entre diferentes grupos étnicos fue una de las características principales (mapa 1). La documentación nos permite trabajar sobre un espacio-tiempo de intermediación construido a partir de denominaciones, delimitaciones y negociaciones que fueron esbozándose a la par de procesos complejos de interdigitación entre diferentes sujetos (Martínez, 1999; Boccara, 2010). Una de las primeras cartas del padre Gaspar Osorio de 1628 desde el territorio chaqueño nos pone sobre aviso:

la cantidad de gente que se dice es cierta; y acá vienen y van caciques [...] hay muchas naciones circunvecinas que hablan diferentes lenguas, y solo de una que voy aprendiendo, me dicen hay más de cincuenta mil; y de lengua mataguay, corren en opinión de treinta mil (Lozano [1733] 1941, p. 164).

Además del relevamiento de recursos naturales ${ }^{4}$, en su recuento etnográfico Osorio reconocía tobas, mocovíes y jadpitalaguas como tres de las provincias más importantes del Chaco, sobre las que deberían formarse tres reducciones cuyo propósito sería conformar la llave a las demás "naciones" chaqueñas, en especial para acceder al territorio de los churumatas, ubicados a dos jornadas de Santiago de Guadalcazar, "hacia el camino del Perú, para donde se saldrá a hacer camino, que será un gran bien para estas provincia" (Lozano [1733] 194, p. 164).

4 En este contexto, luego de las primeras y frustradas entradas realizadas sobre la frontera chaqueña, los jesuitas emprendieron una nueva incursión en 1638 a cargo de los padres Gaspar Osorio y Felipe Medina. Tanto el cronista Lozano como otros documentos indican que la primera estadía de estos misioneros se produjo entre los indios ocloyas encomendados a Juan Ochoa de Zárate ${ }^{5}$. La permanencia de los misioneros no estuvo exenta de conflictos, y a unos pocos meses, tras un incidente con el franciscano Francisco Truxillo y la desafortunada circulación de algunos escritos "libelosos" en contra de la Compañía ${ }^{6}$, aparentemente motivado por disputas entre las órdenes, la misión de Osorio partió en 1639 hacia el Chaco en compañía esta vez del padre Antonio Ripario y un estudiante llamado Sebastián Alarcón. Una vez asentados en territorio de los indios palomos, los caciques Salapirin y Helichorin, quienes habían acudido al paraje "en demanda de los indios palomos" y en busca de "matalotaje", posiblemente desde la frontera de Tarija, acabaron con los misioneros luego de dos días de convivencia entre ellos y de recibir algunos obsequios de parte de los padres ${ }^{7}$. 
Mapa 1: Provincia jesuítica del Paraguay y sitio de la muerte de los misioneros. Elaboración propia en base al mapa de Antonio Machoni publicado en la Descripción chorográfica del Gran Chaco Gualamba, de Pedro Lozano (1733). Biblioteca Nacional Argentina, Tesoro.

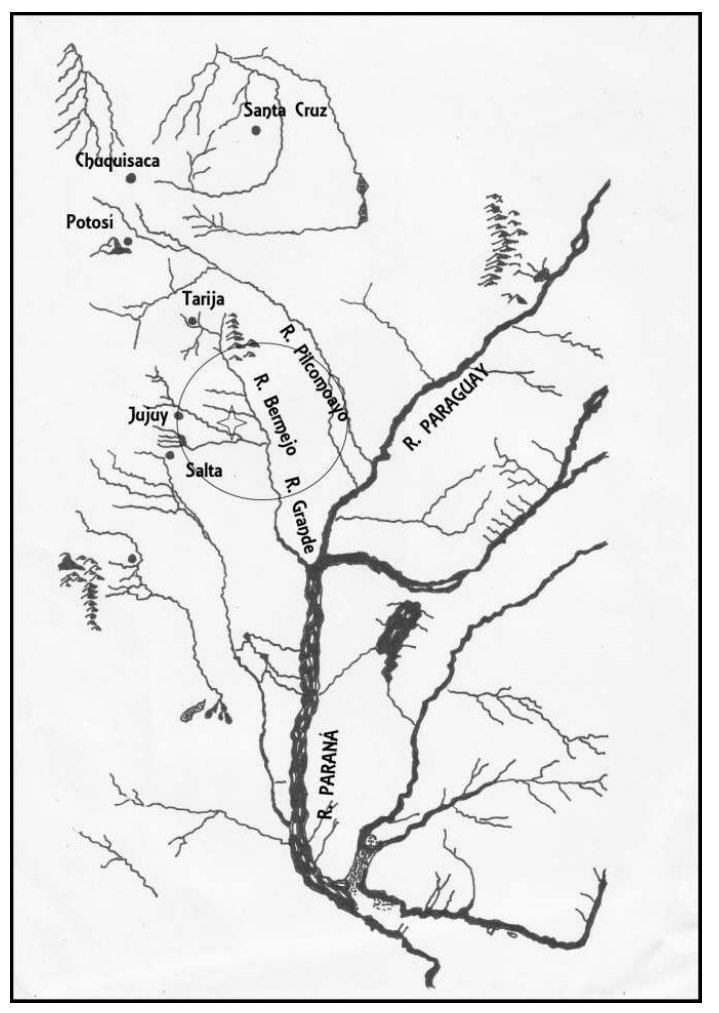

5 Poco tiempo después, por petición del obispo Maldonado y Saavedra, el teniente gobernador Fabián Morillo se dispuso a ejecutar el pedido de información sobre el martirio de estos religiosos. El documento, habitual ante casos similares ${ }^{8}$, debe ubicarse entre los requerimientos que desde el pontificado de Urbano VIII debían cumplirse puntualmente en un proceso ordinario de beatificación. El obispo debía ser el primero en proporcionar la información necesaria sobre la vida y muerte del candidato a la santidad por medio de un interrogatorio a testigos pertinentes que debería llegar a la Sagrada Congregación de Ritos en Roma, a efectos de dar apertura a la causa (Rubial García, 2001, p. 36). El informe de 1639 perseguía varios fines: por un lado, establecer el lugar de las muertes y los ejecutores de las mismas, el número de naciones con que se habían encontrado y las labores desarrolladas entre estos en procura de su conversión. Por el otro, la obtención de datos precisos sobre la forma del martirio, las causas, el destino de los cuerpos y la posible existencia de milagros y devociones a los restos óseos.

En el proceso indagatorio, llevado a cabo en dos instancias, declararían cinco indígenas registrados con los nombres de Francisco, Pedro Inchiri y Pedro Ynobeile, todos naturales "peluchocos", Alonso Cuchea, natural "labradillo de la nación de los palomos" y un muchacho llamado Lorenzo, natural de Santiago del Estero. Los cuatro primeros pertenecientes a la encomienda de Marcos Cabello y el último encomendado "al heredero de Gerónimo Camargo". El primer interrogatorio sería ejecutado por el teniente gobernador Fabián Morillo, con la asistencia de dos intérpretes, un tal Pedro Cacique, hábil en la lengua de los pelichocos y Pedro Ramos Cañar, lenguaraz en la general del Perú. A la segunda instancia del interrogatorio la llevaría a cabo el capellán Cosme de 
Rivero, cura y vicario de la ciudad de Salta, y oficiarían de intérpretes Juan Coronel y Blas de Chávez.

7 La importancia de la muerte de estos misioneros para la Compañía de Jesús se reflejó en las posteriores elaboraciones hagiográficas, muy similares en contenido, que circularon entre fines del siglo XVII y mediados del siglo XVIII por Europa y América. Muchos de los datos recabados en los informes de 1639-1640 fueron volcados, de manera muy fragmentaria, y difundidos en Europa en obras como Varones ilustres de la Compañía de Jesús , de Juan Eusebio Nieremberg (1647), en el Mortibus Illustribus de Felipe Alegambe (1657), en Anno Dierum memorabilium Societatis Jesu de Juan Nadasi y en el martirologio de Mathias Tanner (1675), en donde se incluyó un grabado representando el momento de las muertes, autoría de Melchior Küsell. Francisco Xarque incluyó algunas noticias al hacer mención a la hagiografía de Antonio Ruiz de Montoya (1662). Lo mismo hicieron Nicolás del Techo en Historia Provinciae Paraquariae (1673) y Pedro Lozano en su Descripción chorográfica (1733) entre otros. En un escenario de conocimientos vagos sobre el espacio a conquistar, estas hagiografías y crónicas proporcionaron también datos fehacientes sobre territorios, habitantes y las posibles estrategias a desplegar en nuevas conversiones por parte de los misioneros (Ledezma y Millones, 2005, p. 28), aunque depurando los relatos de aquellos indicios que pudieran implicar una apropiación peligrosa de algunos elementos de la doctrina cristiana en términos nativos.

\section{Algunas consideraciones sobre el contenido del informe: filtros, agencias y materialidades}

8 El informe es producto de estas circunstancias y no puede analizarse sin hacer referencia a la voluntad prescriptiva del escrito. La especificidad y direccionamiento de las preguntas -que deberían realizarse "con claridad y distinción [...] para que en todo tiempo siempre la verdad y la virtud tenga premio y dar cuenta a su santidad y a su Magd"-, los recurrentes filtros mediadores producidos por la actuación de los intérpretes en lengua de los pelichocos y la general del Perú, de los testigos - de los cuales varios refirieron lo dicho por escuchas de terceros-y del Auto resultante, certificado por Fabián Morillo y los dos testigos Juan Pomposo y Onofre Suarez, "con lo qual se corrigio ha cierto y verdadero, Siendo tes ${ }^{\circ s}$ a lo ver, sacar, corregir y concertar", plantea la necesidad de ciertos recaudos en la lectura de este tipo de documentación, resultante de situaciones concretas de poder en un contexto de dominación que se justificaba en diferencias étnicas y en una teoría de la organización político-social en niveles de civilización (Boccara, 2010).

9 No obstante ello, no debemos olvidar la base textual y dialógica de este tipo de testimonios que nos enfrentan a posibilidades más allá de los filtros deformantes, en tanto es posible reconocer, en la trama hojaldrada de las testificaciones, distintas voces y sujetos (Ginzburg, 2010), inmersos en la fórmula "que digan lo que saben y cómo es que lo saben", de uso corriente en esta clase de indagaciones ${ }^{10}$. El exesivo pesimismo de considerar a los indígenas del pasado como ficciones de la imaginación occidental es, como sugiere Viveiros de Castro, una forma más de etnocentrismo (Viveiros de Castro, 2010, p. 15). Paula Montero ha sugerido en este sentido que, en la medida en que los relatos coloniales se produjeron en el proceso mismo de las relaciones entre los indígenas $\mathrm{y}$ los misioneros ( $\mathrm{u}$ otros agentes coloniales), las fuentes deben ser tratadas como una 
narrativa en la que se depositaron distintas voces, lo cual puede decirnos algunas cosas no tanto de la "originalidad" de los nativos, como de los procesos de encuentro entre esos agentes y la gestación de códigos comunicacionales compartidos (Montero, 2006, p. 13). ${ }^{11}$

10 El pedido de información encargado por Maldonado y Saavedra, sin ser una fuente indígena, nos permite adentrarnos en algunos elementos del universo de representaciones y prácticas rituales de los indígenas que testificaron y de aquellos a los que hicieron referencia en sus testificaciones. Las declaraciones de los indios pelichocos y labradillos reunidas en el documento nos remiten a formas culturales compartidas y a conflictos entre estos grupos que venían produciéndose desde antes de la llegada de los españoles. Estos grupos formaron parte de una de las primeras reducciones de particulares asentadas en los Valles de Jujuy, en las tierras del capitán Francisco Arias en Río Blanco. Sica y Sánchez indican que una de las particularidades de estos grupos fue la conservación de sus tradicionales pautas de subsistencia, lo que redituó a favor de los españoles al no tener que utilizar parte de sus tierras o destinar otras nuevas en la producción de alimentos para su mantención (Sica y Sánchez, 1997, p. 64). Esta permeabilidad territorial permitió a los pelichocos y labradillos mantener comunicación con grupos no reducidos, como bien detalla un documento de 1644 que alude a "juntas" en el río Siancas, en donde "se comunican con los suyos y parientes ya que se hallaron rastros de haber llegado muchos indios y una vincha de palma colgada en un palo" (Sica y Sánchez, 1997, p. 77). En 1644, los pelichocos llevaron a cabo un alzamiento y mataron a varios españoles e indios amigos en Palpalá. Las referencias son escuetas, y hacia el siglo XVIII se tornan aún más escasas, aunque las alusiones al etnónimo aparecen en otras fuentes escritas y cartográficas para hacer mención a estos grupos asentados en otros parajes y sin sujeción a los españoles ${ }^{12}$.

11 Los pelichocos y labradillos mantuvieron contacto en un mismo espacio con palomos, tobas, y chiriguanos. Estos últimos realizaron incursiones desde la primera mitad del siglo XVII hacia las fronteras de Jujuy y Salta en contra de otros grupos y, hacia fines del mismo siglo, acompañando las entradas militares en las que participaron al mando de don Diego Porcel de Pineda desde Tarija ${ }^{13}$. Una Noticia de 1685 nos permite localizar a los chiriguanos más cercanos al espacio tucumano en los pueblos de Cuiambuyo y Tariquea, los que "salen a las entradas del Chaco con los españoles desta Villa todos los años y en las ocasiones que se ofrece alguna paz dellos que los enemigos son muchísimos"14. La complejidad de las conexiones entre grupos diferentes entre los cuales deben interactuar los misioneros delimita una verdadera configuración cultural, es decir, "un marco compartido por actores enfrentados o distintos, de articulaciones complejas de la heterogeneidad social" que se presenta como un campo de posibilidades, con una lógica de interrelación entre las partes y posee una trama simbólica común (Grimson, 2012, pp. 171-194).

12 En ese espacio, los misioneros y los objetos litúrgicos introducidos por ellos adquirieron para los indígenas significados precisos, que tuvieron que ver con representaciones que iban mucho más allá de las enseñanzas cristianas. Un ejemplo claro de esa complejidad fue la actitud de los grupos que se vieron involucrados de una u otra manera en la muerte de los padres y los sucesos posteriores. Como es bien sabido, la apropiación de objetos materiales como artefactos de metal y recursos como el ganado caballar fueron reconfigurando muchas de las prácticas indígenas en el espacio chaqueño. A estos materiales acompañaron otros que fueron introducidos por los misioneros como "bujerías" en las instancias de negociación, o tomados por los grupos chaqueños en el 
curso de los enfrentamientos con españoles y religiosos. De esta manera, santos, vírgenes, cristos, cruces, rosarios y otras materialidades aparentemente menores -agujas, mantas, cuentas, etc.- fueron introducidos también entre grupos de los cuales muchos ya tenían acceso a otros bienes de la sociedad hispano-criolla y reconocían la ventaja -material y simbólica- de acceder a ellos. Cuando el capellán Cosme de Rivero preguntó qué había sucedido después de la muerte de los misioneros, Francisco, uno de los indígenas de la encomienda de Marcos Cabello, contestó, evidenciando un ir y venir de información entre diferentes sujetos:

que lo que save es que acia como un mes poco mas o menos que estando este $t^{\circ}$ en su pueblo de los pelochocos abajo del Rio Ciancas [ilegible] dos indios ynfieles palomos que residen en la parte y lugar donde mataron los dhos padres los quales contaron a este testigo como todos los días estan los dhos Padres como vivos vestidos como quando disen misa resplandesientes y que no es más de un padre el que assi am visto, y que vinieron como dies in ${ }^{\text {os }}$ chiriguanaes avian venido a ver el dho padre que estaba resplandeciente y que con mucho espanto de la vista detuviendosse adonde estaban los demas in ${ }^{\circ s}$ se avian muerto $=\mathrm{y}$ assi mesmo le dijeron los dhos dos indos como los in ${ }^{\circ s}$ que assi avian muerto a los dhos Padres dentro de algún tiempo se avian muerto tambien $=\mathrm{y}$ que $u n \operatorname{In}^{\circ}$ que avia vevido en el caliss con que los padres desian misa avriendose desde la cabeza hasta la camisa revento y murió y asi de miedo desto no an querido mas beber en el dicho caliss y que el cacique lo tiene guardado todo lo qual dixo a este $t^{\circ}$ los dhos dos in ${ }^{\circ s}$ infieles los quales murieron en el Pueblo de este testigo y esto Responde ${ }^{15}$.

13 La problemática de las formas de apropiación de "la cultura material española" tras las primeras incursiones misionales al Chaco ha sido planteada en trabajos recientes (López, 2008), aunque con algunos puntos que merecen un mayor análisis, en la medida en que a pesar de reconocer la importancia de un abordaje en términos de resignificaciones, de plantear el concepto de etnogénesis y avanzar en la introducción de materiales por parte de los jesuitas entre los indígenas "del común" y no solo entre los caciques, esta clase de aportes se reduce a una diferenciación entre "objetos" y "materiales", tomando este último concepto para hacer mención a los procesos productivos de la manufactura de artefactos, su uso y/o consumo y descarte, pero sin abandonar una mirada funcional de estos objetos en relación a la evangelización, sin avanzar en los posibles horizontes de significación en que estas materialidades fueron apropiadas y no solamente introducidas, o, en palabras de Latour, sin focalizar el poder agenciativo de estos objetos.

Aportes claves han resultado los de la etnografía amazonista, que ha señalado la necesidad de no aplicar la diferenciación clásica occidental entre naturaleza y cultura al estudio de sociedades indígenas de tierras bajas, en la medida en que en sistemas anímicos como estos, humanos y no humanos pueden compartir atributos de persona (Viveiro de Castro, 2004; Descola, 2011). Latour, por su parte, ha insistido, al remarcar que los objetos también tienen capacidad de agencia, que el reconocimiento de los objetos como actores o actuantes permite explicar las asimetrías de las relaciones sociales en las que esos objetos intervienen (Latour, 2008, p. 108). Detenernos sobre estas materialidades y en la importancia de los agentes liminares que actuaron junto a ellas en espacios como este nos puede permitir ingresar en un problema mucho más complejo que es el del cambio cultural y los procesos de conversión desatados en los espacios fronterizos. Estamos, así, en un contexto y ante situación de incorporación de elementos culturales alógenos por parte de los grupos que implicaron prácticas concretas de apropiación de la diferencia, lo que nos permite aparatarnos de una mirada demasiado anclada en el binomio aculturación/resistencia (Boccara, 2005). Las relaciones hiladas entre los sujetos 
que habitaron la unión de los ríos Perico y Siancas nos hablan de procesos de gestación continua de identidades, en donde nos encontramos con articulaciones, comunicaciones y mediaciones entre mundos culturales entramados en los que los sujetos responden de maneras diferentes o incluso combinadas ante determinadas situaciones, que pudieron ser, como remarcó Estensoro (2001), para el Perú, de fusión-asimilación o de rechazoseparación, pero que en la mayoría de los casos implicaron apropiaciones y traducciones ambiguas.

Sabemos que la muerte de los jesuitas Osorio y Ripario activó, sin necesidad de que el caso llegara a la Sagrada Congregación de Ritos en Roma, una serie de prácticas que insinúan tenuemente un culto a los misioneros ${ }^{16}$, pero queda abierta la pregunta sobre qué procesos pudo desatar hacia el interior de los grupos indígenas esta clase de sucesos en el espacio chaqueño. Lozano advierte que tras la muerte de los padres y la noticia de las apariciones y el milagro del cáliz que "el cacique lo tiene guardado", los palomos "movidos de su fama" solicitaron la entrada de nuevos misioneros con la mediación de un indio cristiano de Humahuaca, un tal Lorenso Cacat, "que solía a veces entrar a sus tierras" (Lozano, [1733] 1941, p. 179). El problema de las formas de apropiación que los indígenas realizaron de las materialidades sagradas de los cristianos y de la imagen de los jesuitas como "hombres santos", que en una variedad de casos que van desde el Paraguay a la chiriguanía, estuvo vinculado a las disputas por el monopolio de lo sagrado y el poder chamánico (Pompa, 2010; Castelneau L'Estoile, 2011; Geres, 2013), y abre una serie de interrogantes sobre las posibilidades de acción de los grupos de indígenas reducidos e "infieles" en la configuración de nuevos espacios culturales, una de las cuestiones para las que esta fuente resulta de sumo interés.

\section{Sobre la transcripción}

El pedido de información se encuentra contenido en un conjunto documental existente en la Sala IX del Archivo General de la Nación. Los documentos de nuestro interés se encuentran entre los folios $38 \mathrm{r}$ al $64 \mathrm{r}$ del original, por lo que respetamos esta secuencia en la foliación. En cuanto a las normas empleadas en la transcripción, la grafía original ha sido respetada, realizándose solamente en algunos casos la separación gramatical de las palabras encadenadas y la unión de los vocablos separados. El uso de las mayúsculas se mantuvo de acuerdo al documento. La indicación [ilegible] señala aquellos términos individuales que no han podido ser transcriptos por dificultad de lectura, mientras que los puntos suspensivos [...] refieren a dos o más términos que no logramos descifrar. Las palabras tachadas en el original se han reproducido de la misma forma. En todo momento los apelativos étnicos y nombres de lugares han sido respetados de acuerdo a la grafía original. Ello ha obedecido a una opción metodológica, entendiendo, como sugiere Pompa, que la transcripción debe realizarse de forma suficientemente amplia para devolvernos un triple contexto: "el contexto histórico en que se producirán los acontecimientos; el contexto narrativo en que se articulan las informaciones; el contexto cultural para el cual los relatos eran destinados" (Pompa, 2003, p. 29). La opción de incluir las cartas que inician la transcripción, en donde se solicitan misioneros y posteriormente el pedido de información, responde, de la misma manera, a una necesidad de describir lo más densamente posible el contexto en el que el informe se produjo. La información, por último, fue relevada en el marco del desarrollo de una investigación más amplia abocada a las representaciones y prácticas en torno a la santidad en el espacio chaqueño durante 
los siglos XVII y XVIII, la que cuenta con financiamiento del Consejo Nacional de Investigaciones Científicas y Técnicas ${ }^{17}$.

\section{BIBLIOGRAFÍA}

Boccara, G. (2005). Génesis y estructura de los complejos fronterizos euro-indígenas. Repensando los márgenes americanos a partir (y más allá) de la obra de Nathan Wachtel. Memoria americana, 13, 21-52.

Boccara, G. (2010). Antropología política en los márgenes del Nuevo Mundo. Categorías coloniales, tipologías antropológicas y producción de la diferencia. En C. Giudecelli, Fronteras movedizas. Clasificaciones coloniales y dinámicas socioculturales en las fronteras americanas, (pp. 103-135). México: Centro de Estudios Mexicanos y Centroamericanos, El Colegio de Michoacán, Casa de Velázquez.

Castelnau- L'Estoile, C. (2011). Compartir las reliquias. Indios tupíes y jesuitas frente a los huesos de un misionero chamán en el Brasil de inicios del siglo XVII. En G. Wilde (Ed.), Saberes de la conversión. Jesuitas, indígenas e imperios coloniales en las fronteras de la cristiandad, (pp. 225-250), Buenos Aires: SB.

Chaile, T. (2011). Devociones religiosas, procesos de identidad y relaciones de poder en Salta. Desde la colonia hasta principios del siglo XX. Salta: Capacitar del NOA.

Descola, P. (2011). Más allá de la naturaleza y de la cultura. En L. Montenegro Martínez (Ed.), Cultura y naturaleza. Aproximaciones a propósito del bicentenario de la independencia de Colombia, (pp. 54-77). Bogotá: Jardín Botánico de Bogotá.

Estensoro, J. C. (2001). El simio de Dios. Los indígenas y la Iglesia frente a la evangelización del Perú, siglos XVI-XVII. Bulletin de l'Institute francais d'estudes andines, 30, 455-474.

Gamboa, M. (2008) De la ergonomía a la antropología y viceversa. La materialidad de los 'objetos' y sus implicaciones. En S. Romero Gorski, Anuario Antropología social y cultural en Uruguay 2008-2009, (pp. 79-86). Montevideo: Nordan-Comunidad.

Ginzburg, C. (2010). El inquisidor como antropólogo. En El hilo y las huellas. Lo verdadero, lo falso, lo ficticio, (pp. 395-411). Buenos Aires: FCE.

Geres, O. (2013). Con eficacia para semejantes cosas... Martirio, ritualidad y poder en las misiones de indios chiriguanos. Siglo XVIII. Dimensión Antropológica, 52, en prensa.

Grimson, A. (2012). Los límites de la cultura. Crítica de las teorías de la identidad. Buenos Aires: FCE.

Hampe Martínez, T. (1997). Los testigos de Santa Rosa (Una aproximación social a la identidad criolla en el Perú colonial. Revista Complutense de Historia, 23, 13-136.

Latour, B. (2008). Reensamblar lo social. Una introducción a la teoría del actor-red. Buenos Aires: Manantial.

López, M. (2008). Análisis de la cultura material en documentación jesuita édita e inédita referida a la Mision de Omaguacas en la región del Tucumán. En VI Congreso Argentino de Americanistas, tomo II, Buenos Aires, Sociedad Argentina de Americanistas (pp. 237-261). http:// 
www.academia.edu/622892/

_Analisis_de_la_cultura_material_en_documentacion_jesuita_edita_e_inedita_referida_a_la_Mision_de_Omaguacas_en_la_region_del

Martínez, J. L. (2009). Ayllus e identidades interdigitadas. Las sociedades de la puna salada. En G. Boccara y S. Galindo, Lógica mestiza en América, (pp. 85-112). Temuco, Chile: Instituto de Estudios Indígenas.

Montero, P. (2006). Introdução. Missionários, índios e mediação cultural. En Deus na aldeia. Missionários, índios e mediação cultural. São Paulo: Globo.

Morillo, F. ([1780] 1833). Diario del Viaje al río Bermejo. En Colección de obras y documentos relativos a la historia antigua y moderna de las Provincias del Río de la Plata, ilustrado con notas y disertaciones por Pedro de Ángelis. Tomo VI. Buenos Aires: Imprenta del Estado.

Oliveira, P. R. M. de. (2010). o encontro entre os guarani e os jesuítas do Paraguai e o glorioso martírio do venerável padre Roque González de Santa Cruz nas terras de Ñezu. Tese doutoral. Universidade Federal do Rio Grande do Sul. Instituto de Filosofia e Ciências Humanas. Programa de Pós-Graduação em História. Disponible online em Repositório Institucional do Universidade Federal do Rio Grande do Sul. http://www.lume.ufrgs.br/handle/10183/21462.

Pompa, C. (2011). Conversões indígenas: poder simbólico e razão prática no sertão colonial. En A. Agnolin et al (Orgs.), Contextos missionários. Religião e poder no Império Português. São Paulo: Editora HUCITEC.

Rubial García, A. (2011). La santidad controvertida. Hagiografía y conciencia criolla alrededor de los venerables no canonizados de Nueva España. México: UNAM - FCE.

Sánchez, S. y Sica, G. (1997). Por ser gente de otra ley. Tobas, mocovíes y ojotaes reducidos en el valle de Jujuy. Prácticas y discursos (siglos XVII y XVIII). Journal de la Societé des Américanistes, 83, 59-80.

Viveiros de Castro, E. (2004). Perspectivismo e multinaturalismo na America indígena. O que nos faz pensar, 18, 225-254.

Viveiros de Castro, E. (2010). Metafísicas caníbales. Líneas de antropología postestructural. Buenos Aires: Katz.

Wilde, G. (2008). El enigma sonoro de Trinidad: ensayo de etnomusicología histórica. Resonancias, $23,41-66$

Xarque, F. ([1687] 2008). Las misiones jesuíticas en 1687. El estado que al presente gozan las Misiones de la Compañía de Jesús en la Provincia del Paraguay, Tucumán y Río de la Plata. Buenos Aires: Academia Nacional de la Historia. Unión Académique Internationale.

\section{ANEXOS}

\section{ARCHIVO GENERAL DE LA NACIÓN}

SALA IX: 26-4-3: Pedido de información sobre el martirio de los padres Gaspar Osorio de Valderrábano y Antonio Ripario, 1639-1640. 


\section{[Folio $38 \mathrm{r}$ ]}

Frai Melchor del Orden de mi $\mathrm{P}^{\mathrm{e}}$ San Agustin nro $\mathrm{P}^{\mathrm{e}}$ Por la gracia de Dios y de la $\mathrm{S}^{\text {ta }}$ Sede Apos $^{\text {ca }}$ obpo de la Cathedral del Tucuman y del Consejo de mu Magd \&

A nros vicarios de las ciud ${ }^{\text {des }}$ de San Salvador de Jujui, Valle de lerma y nueba Talavera de Madrid Salud en nro $p^{e}$ Jesuxpto saved que estando la Comp ${ }^{a}$ de JSH junta en su congregacion en esta ciudad de Cordova valiendonos de su estatuto [ilegible] en la Conbersion de las animas de mis obejas y predicacion evangelica les embiamos en ejercito del señor [...] Frai Melchor del orden de mi $\mathrm{P}^{\mathrm{e}}$ san Agustin Por la gracia de Dios y de la $\mathrm{S}^{\text {ta }}$ Sede Aphostolica Obispo de la Cathedral de Tucuman del Consejo de su mag ${ }^{\mathrm{d}}$ al $\mathrm{P}^{\mathrm{e}}$ Diego de Boroa Pro de la Comp ${ }^{\text {a }}$ de JHS en esta Prob ${ }^{a}$ del tucuman Paraguai y Rio de la Plata salud en nro Pe Jesuxpto sabra VR [ilegible] debe saber y le tenemos comunicado y entre los dos conferido muchas veces la necesidad grande que en esta Prov ${ }^{\mathrm{a}}$ ay de ministros evangelicos para predicar y administrar los sacram ${ }^{\text {tos }}$ a nras ovejas en particular a los indios que ya están convertidos y baptizados y para llamar al conocim ${ }^{\text {to }}$ de Dios y de su $\mathrm{S}^{\text {to }}$ evangelio a los que están fuera de la Igl ${ }^{a}$ y que en las doctrinas que ai de gente baptizada es tan grande la falta de operarios que ai distancia, con mas de mill y trecientas almas en una sola reducion sin que vengan cura que los doctrine y confiese ni le aya enviado el obispado capaz y ai otras que aunq ${ }^{\mathrm{e}}$ le tienen son tan largos en la distancia que es imposible un clérigo solo poderlo hacer como era raçon de mas de lo que emos [ilegible] muchas faltas irremediables en algas $\mathrm{p}^{\text {tes }}$ de que le tenemos dado cuenta a su Magd ${ }^{\mathrm{d}}$ se la damos a su Santidad y ansi mismo ay en los cerros y terminos de esta ciudad nra diócesis grandiss ${ }^{\circ s}$ centenares de millares de animas por convertirse a nra Sta Fee catholica y entre algas Prov $^{\text {as }}$ ay principio de predicación del evangelio y conocida experiencia de buenos nortes y considerando que por cada uno de estos infieles y de los ya convertidos Jesuxpto nro $\mathrm{P}^{\mathrm{e}}$ derramo su sangre y que sin la heredad que le dio su $\mathrm{P}^{\mathrm{e}}$ y que a nra [ilegible]

\section{[Folio $38 \mathrm{v}]$}

pequeñes se dignó encargar esta Igla para que en ella cuidesemos de predicar a su evangelio de dar a conocer su $\mathrm{S}^{\text {to }}$ nombre y como nos creo y redimió y la lei de nos dio y que mas a de juzgar premiandonos en su juicio o castigándonos segun nras obras y que mas obliga a peca ${ }^{\mathrm{do}}$ mortal el predicar lo sobredicho sabiendo que los ya convertidos se conserven en la pureza del baptismo y llamando a los que no lo están a que lo reciban y que donde no pudieremos por ntra persona lo devemos encargar a otras Personas dignas y no perder medio ni diligencia humana para que estos miserables ynfieles conozcan a dios y consigan la buena benturança y [ilegible] la satisfacion que tenemos a la Comp ${ }^{a}$ de Jesus y del celo con que cuida de la honra de Dios y de la conversion de las almas por lo que emos hallado en esta $\mathrm{p}^{\text {te }}$ que a sido de este obispado servida la Igla ${ }^{\text {a }}$ Por la dicha Relign en tiempo de nros antecesores ayudándoles en las missiones y en la predicación de los infieles y generalm ${ }^{\text {te }}$ en todas las ciudades asistiendo a todas horas del dia y de la noche a las necesidades espirituales de todo genero de gente y porque assi nos lo tiene prometido V.R le exortamos de $\mathrm{p}^{\text {te }}$ de su Mag ${ }^{\mathrm{d}}$ como Patron de su Iglesia y de parte de Dios que es Señor que todo lo puede pagar en igualdad el merito de tan grande obra y de nra parte le pedimos y se lo rogamos que hagan a nro Señor y a su Iglesia este servicio y [roto] su Religion junta en Congregacion en esta ciudad y an de ir y repartirse por toda esta 
diocesis escoja los sujetos que hallase mas capaces y les cometa la predicacion del evangelio a los infieles y en las partes donde no se ha predicado y donde se a comenzado a predicar para que vaian como tales predicadores Evangelicos dando a conocer en nombre de Dios y ansi mismo a estos operarios cometa el ir corriendo las doctrinas valles estancias y términos donde ubiese gente conbertida y baptizada que vaian confesando predicando y administrando [ilegible] los $\mathrm{s}^{\text {tos }}$ sacram $^{\text {tos }}$ y el del matrimonio haciendo officio de curas que a los que V.R aprovase y hallase capaces y señalase para los efectos desde luego los señalamos

\section{[Folio 39 r]}

aprobamos y damos el poder en derecho necesario [ilegible] para esto lo sobredicho y descargamos en esta nra conciencia en la de V.R en quanto a la suficiencia con que los casam $^{\text {tos }}$ que se hicieren sea presediendo pleno conocimiento de que no ai legitimo impedimento y llevando los nombres escritos con dia mes y año Padres y padrinos para darselos al cura de aquella parte o al vicario de la ciudad que se los embie para que los escriba en su nombre y siempre conste y lo mismo para los baptizados = y mandamos a todos y qualesquier estado calidad y condición que sean en virtud de santa obediencia y so pena de descomunion maior una pro trina canonica monitione praemisa ipso facto incurrenda y de cien $\mathrm{p}^{\mathrm{s}}$ para la $\mathrm{s}^{\text {ta }}$ cruzada y gastos de estrados de permitir que den todo el favor y aiuda ness ${ }^{\mathrm{a}} \mathrm{y}$ no pongan impedimentos directo ni indirecto para la execucion dejando siempre a los religiosos que llevaran nombramiento de V.R y testimonio de estas nras letras de qualquier escrivano notario publico dados en la ciudad de Cordoba en siete días del mes de Agosto de mil y seicientos y treinta y siete años firmadas de nra mano y refrendadas de nro secretario y selladas con el sello maior de nras armas. Frai Melchor Maldonado obispo de Tucuman por mandato del obpo mi señor el $\mathrm{D}^{\text {or }}$ Adrian Cornejo Secretario

[al margen:] Resp ${ }^{\text {ta }}$ del $\mathrm{P}^{\mathrm{e}} \mathrm{P}$. Aviendo visto y leído la orden q [traía] de VSS ${ }^{\mathrm{a}} \mathrm{Il}^{\mathrm{ma}}$ en esta congregacion y reconocido en ella el santo celo y deseo que VSSa tienen del bien de las almas y que Dios nro $\mathrm{S}^{\mathrm{r}}$ sea conosido de todos dimos gracias a nro Senior viendo que los hijos de esta Comp ${ }^{a}$ pudiesen con su pequeñez y [ilegible] servir en algo a su Iglesia y a VSS $^{\mathrm{a}} \mathrm{Il}^{\mathrm{ma}}$ y assi aunq ${ }^{\mathrm{e}}$ al presente se halla esta Prov ${ }^{\mathrm{a}}$ con gran falta se sujetos por aver faltado muchos operarios con los [ilegible]

\section{[Folio $39 \mathrm{v}$ ]}

y continuos trabajos y estar repartidos en las missiones de las Provincias del paraguai en el Parana y Uruiay y en la Prova del Tape y en la de los Itatines cinquenta y dos religiosos que están ocupados en la conversion de los naturales dellas y las casas y colegios con tan poco numero de sujetos Por estar como a VSS $\mathrm{Ilm}^{\mathrm{a}}[$ [...] a dado orden que se acuda a la necesidad presente como VSS ${ }^{\mathrm{a}}$ lo pide y señalo para que envien en missiones en la Ciudad de Santhiago del estero Rio Salado y dulce a los $P^{\text {es }}$ Diego Barrios y Baltasar Abadia y para los indios diaguitas de la Rioja a los $\mathrm{P}^{\mathrm{es}}$ fran $^{\mathrm{co}}$ Hurtado y Her ${ }^{\mathrm{do}}$ de Torreblanca y para el [ilegible] de San Miguel de Tucuman a los Pes Joseps Ordones y Ant $^{\circ}$ Masera y por la Prov ${ }^{a}$ del Chaco y términos de Jujuy a los Padres Gaspar Ossorio Pedro Pimentel Ignacio de Medina y para estos de Cordova a los padres Pedro de Herrera y Po Patricio para que todos acudan a lo que VSS ${ }^{\mathrm{a}} \mathrm{Yl}^{\mathrm{ma}}$ manda. En el [ilegible] que su magd catholica se sirve de dar 
licencia que de [ilegible] vengan mas operarios del evangelio con que se podrá acudir a los indios del Valle Calchaquí y demás partes de la Prov ${ }^{\mathrm{a}} \mathrm{y}$ dar mas sujetos a la Prov ${ }^{\mathrm{a}}$ del Chaco como VS ${ }^{a}$ lo pide y manda $=$ Diego de Boroa.

y en su virtud de dhos nuevos ordenes y facultades que dimos ocurriendo con ellos a particulares necesidades que nos pidieran remedio [ilegible] a los indios ocloias con sus dos Comp ${ }^{o s}$ el $\mathrm{P}^{\mathrm{e}} \mathrm{Gaspar}$ Ossorio religioso de la dicha Religion varon conocido por su vida ejemplar y de grande

\section{[Folio $40 \mathrm{r}$ ]}

y encendido celo de la salvación de las almas y de dar a conocer el nombre de Dios a los gentiles para lo que nos consta que se dispuso con ayunos oraciones y actos de mortificación procurando alcanzar de Dios gracia para dar a conocer y hacer el oficio de Apostol y de los dichos ocloias trabajo mucho, los dispuso a que se redujesen comenzaran a reducir a población vida comun y xptiana y de allí entro mas adentro en busca de las prov ${ }^{\text {as }}$ del Chaco y en ciento de feroces poblaciones y naciones entre los cuales predico y algunos le admitían y otros haciendo escarnio de las bestiduras sacerdotales y de lo que predicaba y enseñaba y en odio dello le mataron y a sus compañeros dejando aquella tierra regada con su sangre confesando en el lecho que la derramaban por honra y gloria de Xpto nro Redemptor y dejándonos confiança de su salvación y de que debe ser semilla de abundantes cosechas de fieles en aquellas partes pues tienen ya en la presencia de Dios quien ruegue por sus abitadores y para que en todo tiempo siempre la verdad y la virtud tenga premio y dar cuenta a su santidad y a su Magd nos a parecido que devemos mandar hacer información

Por donde os encargamos a cada uno de Vos y os mandamos que en vros distritos en los que entrase y ocurriesen las noticias de los sobre dicho hagáis información y examinéis los testigos que concurrieren nombrando para lo que fueren dos Ynterpretes q pudiendo ser sean españoles y les

\section{[Folio $40 \mathrm{v}$ ]}

pregunteis las cosas siguientes.

1- Primeramente si conocen y conocieren al dho $\mathrm{P}^{\mathrm{e}} \mathrm{Gaspar}$ Osorio y a sus compañeros y que es lo que saben de su modo de vida y lo que conocieron del celo de predicar el evangelio digan lo que saben y como lo saben.

2- lo segundo si saben que entro en los ocloias y quien entro con el con orden del obispo y de sus prelados a la conbercion de aquellas gentes y hiso mucho fruto y los comenzó a reducir a poblado Vida comun y xpana digan lo que saben y como lo saben.

3- Ytem si saben que dexando [ilegible] aquella reducion entro con los dichos compañeros Apostolicamente la tierra adentro en demanda de las Provincias del Chaco y a su conbersion y a darles a conocer el nombre de Dios digan lo que saben y como lo saben.

4- Ytem si saben que encontraron en algunas naciones de infieles a quienes predicaron el evangelio y dieron noticia de Dios y que de unos fueron bien recibidos y otros hicieron escarnio y en odio de lo que enseñaban los mataron y que modo de muerte les dieron digan lo que saben y como lo saben. 
5- Ytem si saben que despues de haber sucedido lo sobredicho haya hecho Dios algún castigo y demostración de los agresores que castigo y demostración a sido digan lo que saben y como lo saben.

6- ytem si saben si los agresores o otra nación de aquellos aya hecho alguna demostración en los cuerpos y tenidoles alguna beneracion digan lo que saben y como lo saben.

\section{[Folio 41 r]}

7- ytem si saben si les dieron sepultura y que sepultura les dieron si se an corrompido o si estan enteros y si a hecho Dios con ellos alguna demostración de honra y gloria suia y en que parte estan que distancia de nras ciudades que sera menester para sacarlos y traerlos a darles eclesiastica sepultura digan lo que saben y digan assi mesmo de [ilegible].

Por las dhas preguntas con claridad y distinción en cada uno dellas examinareis los testigos que supieran de la materia y el que primero reciviere esta nra carta le embiara al otro en cuio distrito cae la cossa mas cercana y mas notoria della y os quedareis con un testimonio y valdra lo mesmo q el original y en su virtud procederéis a la dha inforon $y$ acumulareis a lo que hiciereles qualquiera informaciones q se avran hecho por qualesquier jus ${ }^{\text {as }}$ eclesipticas y $\mathrm{R}^{\text {les }} \mathrm{y}$ todo en lo original que hicierenles [...] vro parecer $\mathrm{y}$ sentim $^{\text {to }}$ cerrado y sellado lo remitiréis a nro Provisor y Vicario $G^{1}$ para que nos lo embie y para en caso que sea necess ${ }^{\circ}$ compulsar algnos papeles y compeler algos testigos a que declaren procederéis en penas y sensuras y los demas remedios del derecho q para ello y para todo sobre dicho os damos el poder de derecho ness ${ }^{\circ}$ y [ilegible] firmados de nra mano y refrendadas de nro secretario en la ciudad de Cordova diesisiete de enero de mil y seiscientos y quarenta años $=[. .$.

en la ciu de Lerma en veintiocho de marzo de mill y seiscientos cuarenta años yo don Fran $^{\text {co }}$ de Leyva y Mercado not ${ }^{\circ}$

\section{[Folio $41 \mathrm{v}$ ]}

publico del juzgado eclesiástico desta $\mathrm{Ciu}^{\mathrm{d}}$ y su jurisdic ${ }^{\mathrm{n}}$ [ilegible] Balz ${ }^{\text {ar }} \mathrm{Bar}^{\mathrm{me}}$ de $\mathrm{R}^{\mathrm{a}}$ Cortes Cura y vic $^{\circ}$ desta $\mathrm{Ciu}^{\mathrm{d}}$ [ilegible] que para este efecto [ilegible] y concerto corrigio a sierto y verd $^{\circ}$ siendo testigos a lo ver sacar y concertar el Bller Bar ${ }^{m e}[. .$.$] y el dho S^{o r}$ vic $^{\circ}$ para su validación [ilegible] puso en el su autoridad y decreto [ilegible] cuanto puede [...] y lo firmo a que de su nombre en fe de lo qual [ilegible] mi firma acostumbrada

B Bar ${ }^{\text {me }}$ de $\mathrm{R}^{\mathrm{a}}$ Cortes [rubrica]

don Fran ${ }^{\circ}$ de leyba Merlo [rubrica]

En la Ciu ${ }^{\mathrm{d}}$ de lerma valle de Salta en beinte y quatro días del mes de abril de mil y seis cientos y quarenta años el $\mathrm{s}^{\mathrm{r}}$ Bltzar Bar ${ }^{\mathrm{me}}$ de $\mathrm{R}^{\mathrm{a}}$ Cortes cura y vic della y su juridicion= dixo que para comenzar a las inform ${ }^{\text {on }}$ que su ss $^{\mathrm{a}}$ Ilustris $^{\mathrm{a}} \mathrm{m}^{\mathrm{da}}$ se hagan en virtud de los recaudos Precedentes y que los testigos naturales se examinen con toda justific ${ }^{\text {on }}$ nombro su $\mathrm{m}^{\mathrm{d}}$ por interpretes en ella a $\mathrm{J}^{\mathrm{n}}$ Coronel y a Blas de Chaves a quienes $\mathrm{m}^{\text {do }}$ lo aseten $\mathrm{y}$ hagan juram ${ }^{\text {to }}$ acostumbrado y estando Pres ${ }^{\text {tes }}$ los suso dhos lo asetaron y juraron interpretar fiel y verdaderam ${ }^{\text {te }}$ y si asi no hicieren les aiude Dios y al contr $^{\circ}$ se lo demande $y$ lo firmo el dho Juan Coronel y el dho Blas no firmo por no saber escribir 


\section{[Folio 42 r]}

Firmo lo su $\mathrm{m}^{\mathrm{d}}$ del $\mathrm{s}^{\mathrm{r}}$ vicario

Bart $^{\text {me }}$ de $\mathrm{R}^{\mathrm{a}}$ Cortes [rubrica]

Juan coronel

Ante mi Don Fran ${ }^{\circ}$ de leyva Merlo

Notario [rubrica]

Probanza

En la Ciu de lerma valle de salta en veinte y cinco del mes de abril de mil y seis cientos y quarenta años el $\mathrm{S}^{\text {or }}$ Bttar $\mathrm{Bar}^{\mathrm{me}}$ de $\mathrm{R}^{\mathrm{a}}$ Cortes cura y vicario della y su jurisdic ${ }^{\text {on }}=$ dixo que por orden de su SS ${ }^{a}$ Yllma deste obispado se trata hacer siertas averiguaciones en la razón de las muertes del $\mathrm{P}^{\mathrm{e}}$ Gaspar ossorio y sus Compañeros de la Comp ${ }^{\mathrm{a}}$ del nombre de Jesus en la qual combiene al serv $^{\circ}$ del Dios nro $\mathrm{S}^{\text {or }}$ declare un in ${ }^{\circ}$ nombrado fro ${ }^{\text {co }}$ de la encomi ${ }^{\text {da }}$ de marcos Cavello por ser citado en las que sean hecho en esta ciud ${ }^{\mathrm{d}}$ de S. Salvador de Jujuy y para que tenga effecto $=\mathrm{m}^{\text {do }}$ se notifique del dho marcos Cavello para que dentro de quatro días trayga ante $\mathrm{su}^{\mathrm{d}}$ el dho in ${ }^{\circ} \mathrm{fr}^{\circ}$ de su encom ${ }^{\mathrm{da}}$ para el dho efecto y lo cumpla en virtud des ${ }^{\text {ta }}$ obediencia y pena de excom ${ }^{\text {on }} \mathrm{m}^{\text {or }}$ y veinte pesos para la $\mathrm{s}^{\text {ta }}$ cruzada y lo firmo.

Bar $^{\text {me }}$ de la Corte [rubrica]

don Franc ${ }^{\circ}$ de leyva merlo

not $^{\circ}[$ rubrica $]$

\section{[Folio $42 \mathrm{v}$ ]}

En el mismo dia mes y año dichos notifique el auto del dicho ${ }^{\text {or }}$ Vicario leyendoselo Marcos Cavello en su persona y dijo que lo oya testigo gaspar Rodrigues y dello doy fe.

Don Fran ${ }^{\text {co }}$ de leyva Merlo

Not $^{\circ}[$ rubrica $]$

[al margen] $\mathrm{t}^{\mathrm{o}} \mathrm{Fr}^{\mathrm{o}} \mathrm{In}^{\mathrm{o}}$ de la encom ${ }^{\mathrm{da}}$ de marcos Cavello. En la Ciu ${ }^{\mathrm{d}}$ de lerma del Valle de Salta en veintinueve días del mes de avril mil y seyscientos y quarenta años. El $\mathrm{s}^{\mathrm{r}}$ capellan $\mathrm{Cos}^{\mathrm{me}}$ de Rivero Cortes cura y vicario desta $\mathrm{ciu}^{\mathrm{d}}$ para prueba de lo contenido en las preguntas del interrogtorio y en conformidad de lo mandado por su $\mathrm{m}^{\mathrm{d}}$ del $\mathrm{S}^{\text {or }}$ obispo deste obispado hizo parecer antessi a un Yndio que por ynterpretass ${ }^{\text {on }}$ de los dhos $\mathrm{Ju}^{\mathrm{n}}$ Coronel y Blas de Chaves interpretes dixo llamarsse Fran ${ }^{\mathrm{co}}$ [ilegible] natural peluchoco de la encomienda de marcos cavello vesino desta ciu ${ }^{\mathrm{d}}$ del qual dicho indio por dichos interpretes fue recivido juramento a Dios y a una cruz según forma de $\mathrm{d}^{\circ}$ so cargo [ilegible] prometió decir la verdad y siendo preguntado por el tenor de las preguntas del interrogatorio dixo lo sig ${ }^{\text {te }}$.

a la Primer Pregunta dixo que este $t^{\circ}$ no concio al $\mathrm{P}^{\mathrm{e}} \mathrm{Gaspar}^{\mathrm{O}} \mathrm{ss}^{\circ}$ ni a su compañero mas de que tuvo no 


\section{[Folio 43 r]}

ticia dellos y como avian entrado la tierra dentro hacia la Prova del Chaco a predicar y enseñar la Palabra de Dios y esto respondió.

2- a la segunda Pregunta dixo que por $\mathrm{Pub}^{\mathrm{co}}$ y notorio supo este $\mathrm{t}^{\mathrm{o}}$ que dicho $\mathrm{P}^{\mathrm{e}} \mathrm{Gaspar}$ Ossorio entro a los ocloyas y tierra adentro entre jente infiel y la comensso a Reducir y a enseñar la Palabra de Dios y esto responde.

3- a la terecra pregunta = dixo que es $\mathrm{Pub}^{\mathrm{co}}$ y notorio como el dho $\mathrm{P}^{\mathrm{e}} \mathrm{Gaspar} \mathrm{Oss}^{\mathrm{o}}$ y su compañero entraron a la tierra adentro del Chaco entre gente jentil y que marcos gonsalo y Pedro muchacho de el dicho su encomendero dixeron a este $t^{\circ}$ como los dhos padres como personas que fueron con ellos enseñaban a los in ${ }^{\text {os }}$ que topava la palabra de Dios con mucho cuidado y que unos lo tomavan bien y otros no con que avian passado la tierra adentro y toparon con los $\mathrm{Yn}^{\text {os }}$ chiriguanaes que avian venido en demanda de los $\mathrm{Yn}^{\circ \mathrm{s}}$ palomos que consigo estavan los dichos Padres enseñándoles la dotrina y que aquella noche los dichos chiriguanaes trataron de matar a los dhos padres como lo efectuaron otro dia abiendo

\section{[Folio $43 \mathrm{v}$ ]}

aquella media noche muerto al her ${ }^{\text {no }}$ que benia para esta ciu $^{\mathrm{d}}$ por comida llamado Sebastian de alarcon llevando su cabeza entre los $\mathrm{Yn}^{\circ \mathrm{s}}$ y que el dho $\mathrm{P}^{\circ}$ muchacho dixo a este $t^{\circ}$ como aviendo visto la cabeza del dicho her ${ }^{\circ}$ y que los indios en la lengua trataban de matar aquella madrugada a los dhos padres les alerto del casso a que avian respondido que venían a predicar y enseñar la palabra de Dios y los ind ${ }^{o s}$ gentiles que allí estaban sujetos a lo que Dios dispusiesse y assi al amanecer lo avian muerto y que los dichos padres los estaban enseñando y predicando la Palavra de Dios quando los mataron [ilegible] los dichos yndos chiriguanaes no querían oir la palabra de Dios ni Resar y por esto avian tratado las dhas muertes todo lo cual le dixeron a este $t^{\circ}$ los dichos marcos gonsalo y Pedro muchacho y esto responde.

4- a la quarta pregunta= dixo que lo que save es que acia como un mes poco mas o menos que estando este $t^{\circ}$ en su pueblo de los pelochocos abajo del Rio Ciancas

\section{[Folio 44 r]}

[ilegible] dos indios ynfieles palomos que residen en la parte y lugar donde mataron los dhos padres los quales contaron a este testigo como todos los días estan los dhos Padres como vivos vestidos como quando disen misa resplandesientes y que no es más de un padre el que assi am visto, $y$ que vinieron como dies in $^{\text {os }}$ chiriguanaes avian venido a ver el dho padre que estaba resplandeciente y que con mucho espanto de la vista detuviendosse adonde estaban los demas in ${ }^{\circ s}$ se avian muerto $=\mathrm{y}$ assi mesmo le dijeron los dhos dos ind ${ }^{o s}$ como los in ${ }^{o s}$ que assi avian muerto a los dhos Padres dentro de algún tiempo se avian muerto tambien $=\mathrm{y}$ que $\mathrm{un} \mathrm{In}^{\circ}$ que avia vevido en el caliss con que los padres desian misa avriendose desde la cabeza hasta la camisa revento y murió y asi de miedo desto no an querido mas beber en el dicho caliss y que el cacique lo tiene guardado todo lo qual dixo a este $t^{\circ}$ los dhos dos in ${ }^{o s}$ infieles los quales murieron en el Pueblo de este testigo y esto Responde. 
5- a la quinta pregunta dixo

\section{[Folio $44 \mathrm{v}$ ]}

que [ilegible] lo que dijo tiene en la [anterior] de esta y esto responde.

6- a la sesta Pregunta = dixo que no lo ssave y esto responde.

7- a la séptima Prgunta dixo que no lo save todo lo cual es verdad Para el juramen ${ }^{\text {to }}$ que a hecho $\mathrm{n}$ que se afrimo y ratifico aviendosele leydo quienes le tocan las generales paresio por su axpecto de mas de cinquenta años no firmo por no saver ni el interprete fírmelo el dicho $\mathrm{Ju}^{\mathrm{n}}$ coronel ynterprete con el dicho $\mathrm{S}^{\mathrm{r}}$ vicario.

BBarm ${ }^{\text {e de }} \mathrm{R}^{\mathrm{a}}$ Cortes [rubrica]

Juan Coronel [rubrica]

ante mi don Fran ${ }^{\text {co }}$ de leyva Merlo not $^{\mathrm{o}}$ [rubrica].

[al margen] to $\mathrm{P}^{\circ}$ inchiri Natural de pelichoco. En la ciudad de Lerma valle de Salta en primero de maio de mil y seiscientos y quarenta años el dho $\mathrm{s}^{\mathrm{r}}$ vicario para mas inforon hizo parecer ante si a un muchacho que por interpret ${ }^{\text {on }}$ de los dhos interpretes dixo llamarse $\mathrm{P}^{\circ}$ inchiri natural peluchoco de la encomienda de marcos Cavello y ser el citado por $\mathrm{Fr}^{\mathrm{co}}$ testigo del qual se recibio juramento

So cargo del qual prometió decir la verdad y siéndole preguntado por el tenor de las preguntas del interrog ${ }^{\circ}$ dixo lo sigte

\section{[Folio $45 \mathrm{r}$ ]}

a la Primera pregta dixo q este test ${ }^{\circ}$ conosio al $\mathrm{P}^{\mathrm{e}}$ Gaspar ossorio y a sus compañeros como pers $^{\mathrm{a}}$ que les sirvió y entro con ellos desde la ciu de Jujuy hasta el valle del Chaco adentro y donde los mataron y asi vio este test ${ }^{\circ}$ que los dhos $\mathrm{PP}^{\text {es }}$ siempre todos los días desian misa por el camino y resavan y luego que comenzaron a descubrir la $\mathrm{g}^{\text {te }} \mathrm{e} \mathrm{in}^{\mathrm{os}}$ infieles vio este test ${ }^{\circ}$ que con mucho amor y celo de que fuesen xptianos los enseñaban a rezar y los juntavan a que oiesen misa con buenos agasajos predicándoles la palabra de Dios y con este celo entraron a la tierra adentro y esto responde.

2- a la sig ${ }^{\text {te }}$ Preg ${ }^{\text {ta }}$ dixo que no la save porq $q^{\text {do }}$ los dhos padres entraron a los ocloias este testigo no entro con ellos.

3- a la terc ${ }^{\mathrm{a}}$ Preg ${ }^{\text {ta }}$ dixo que dice lo que dicho tiene en la prim ${ }^{\mathrm{a}}$ preg $^{\text {ta }}$ porq $^{\mathrm{e}}$ es verdad que los dhos $\mathrm{P}^{\mathrm{es}}$ entraron a la Probincia adentro del Chaco y este $t^{\circ}$ con ellos y les oia decir que su celo i intento era convertir a todos los in ${ }^{\text {os }}$ de aquella probincia y enseñarles la palabra de Dios como este tg ${ }^{\circ}$ lo bio hacian con todos los in ${ }^{o s}$ que iban topando y descubr ${ }^{\text {do }} \sin$ perder ocac ${ }^{\mathrm{n}}$ de enseñar a rezar y conocer el nombre

\section{[Folio $45 \mathrm{v}$ ]}

de Dios y esto responde.

4- a la quarta pregta dixo ques verdad q los dhos padres de la Comp ${ }^{\mathrm{a}}$ encontraron en su viaje con algunas nasiones de infieles como fueron los palomos y otros a los que les via 
este testg ${ }^{\circ}$ les predicaron y dieron not ${ }^{a}$ de Dios y los llevaron consigo hasta el paraje donde toparon a los indios chiriguanaes a los quales tambien algos días que a lo que se quiere acordar fue desde el sábado hasta el juebes de mañana que los mataron les predicaban y enseñaban la Palabra de Dios llevándoselos consigo quatro jornadas y de la ultima despacharon al $\mathrm{h}^{\text {no }}$ Sebastian de alarcon con dos in $^{\text {os }}$ chiriguanaes a esta $\mathrm{Ciu}^{\mathrm{d}}$ a que llevasen socorro de comida y en este tiempo vio este $\operatorname{tg}^{\circ} \mathrm{q} \operatorname{alg}^{\circ \mathrm{s}} \mathrm{in}^{\mathrm{os}}$ tomaban con amor y voluntad la palabra de Dios y otros hacían escxarnio y causo tener destos odio contra los dhos $P^{\text {es }}$ porque les enseñaban la Palabra de Dios y porque no les daba algas cosas que ellos querían y halla este testigo por sierto y sin duda ninga quela ver muerto a los dhos. Pes fue porque los enseñaban a resar y el modo de muerte que les dieron

\section{[Folio 46 r]}

y lo que paso con ello fue que el miércoles a la noche los dos in ${ }^{\text {os }}$ chiriguanaes que avian venido por matalotaje llegaron adonde estaban los dhos $P^{\mathrm{es}} \mathrm{y}$ los demas ind ${ }^{o s}$ chiriguanaes traiendo la caveza del $\mathrm{h}^{\text {no }}$ Sebastian que lo avian muerto una o dos jornadas atrás y luego vio este tgo $^{\circ}$ que todos los in ${ }^{\circ s}$ se alborotaron y trataron de matar a los dhos $P^{\text {es }}$ con que este $\operatorname{tg}^{\circ}$ les avisso y de cómo avian traido la caveza del dho $\mathrm{h}^{\mathrm{no}}$ a que Respondieron a este testg ${ }^{\circ}$ en la lengua $g^{1}$ hijo nosotros venimos a enseñar la palabra de Dios a estos in ${ }^{\text {os }}$ y lo emos de hacer por Dios aunq nos queste las vidas con que sin deshacer los [ilegible] vestidos los dhos $\mathrm{P}^{\mathrm{es}}$ se recostaron y a sus vistas los dhos in ${ }^{\circ \mathrm{s}}$ les quitaron la caxa en que estaba el sacram ${ }^{\text {to }}$ y se lo llevaron con el calis y otro dia juebes de mañana vido este tg ${ }^{\circ}$ questando los dhos $\mathrm{p}^{\mathrm{es}}$ paseándose cada uno de por si el $\mathrm{P}^{\mathrm{e}}$ osorio en sus oras resando y su Compañero con su rosario vinieron los dhos in $^{\circ s}$ chiriguanaes de sus ranchos a donde estaban los dhos $\mathrm{P}^{\mathrm{es}}$ de mano armada con sus garrotes flechas y lanzas $\mathrm{i}$ los rodearon $\mathrm{y}$ este $\operatorname{tg}^{\circ}$ con otro muchacho se escondieron allí cerca en un montessillo con los in ${ }^{\text {os }}$ palomos y vieron

\section{[Folio $46 \mathrm{v}$ ]}

que con los garrotes mataron prim $^{\circ}$ al $\mathrm{P}^{\mathrm{e}}$ ossorio y luego a su compañero y les quitaron las caveças y asi como los mataron ocurrian los in ${ }^{\circ s}$ sobre los Cuerpos como los cuervos a la carne y les quitaron sus vestiduras dexandolos desnudos en carnes vivas y alsaron Rancho llevándose las caveças y se fueron la tierra adentro con mucha algasara y huelga y ia que se perdieron de vista salvo este $\operatorname{tg}^{\circ}$ y el muchacho y un in ${ }^{\circ}$ viejo Palomo y los tres abrieron una sepultura y ambos cuerpos en uno los enterraron con q este $\operatorname{tg}^{\circ}$ y los in ${ }^{\circ s}$ palomos se vinieron hasta esta ciu ${ }^{\mathrm{d}}$ a dar aviso al español y esto responde.

5- A la quinta Preg ${ }^{\text {ta }}$ que no lo save porq no a buelto mas a su pueblo.

6- a la sesta Preg ${ }^{\text {ta }}$ dixo que no la save.

7- a la séptima preg ${ }^{\text {ta }}$ dixo que dice lo que dicho tiene de la quarta pregunta y que los cuerpos de los dhos padres halla este tgo se podrán traer dentro de veinte días todo lo qual es la verdad para el juram ${ }^{\text {to }} \mathrm{q}$ a hecho en que se afirmo y ratifico aviendosele leído y dado a entender por los dhos interpretes paresio por su aspecto de diez y ocho años poco mas o menos y no hizo 


\section{[Folio 47 r]}

con ninga de las generales que le fueron declaradas no firmo ni el dho Blas de Chaves interprete por no saver firmalo el dho $\mathrm{J}^{\mathrm{n}}$ Coronel y el dho Señor vic ${ }^{\mathrm{o}}$

$\mathrm{BBar}^{\mathrm{me}} \mathrm{R}^{\mathrm{a}}$ Cortes [rubrica]

Juan Coronel [rubrica]

ante mi Don Fran ${ }^{\mathrm{co}}$ de leyva Merlo Not $^{\circ}[$ rubrica]

En la ciudad de Lerma Balle de Salta en veinte y siete días del mes de setiembre de mil y seiscientos y quarenta años el Bachiller Bartolome de Rivera Cortes cura y vicario desta su jurisdicción - digo q por comission y orden espresa de su señoria Yll ${ }^{\mathrm{ma}}$ el señor obpo deste obispado le fue mandado Yciese averiguación y información como consta de [...] un decreto suyo de atras acerca de la muerte del padre Gaspar Osorio y su compañero en la entrada del Chaco y eya se lo remitiese a su señoria Yll $^{\mathrm{ma}}$ y que abiendo puesto toda diligencia sumo en evaeriguar y inquirir testigos que supiesen de las dhas muertes de los dhos padres para la dha información y no aver allado mas que los dos testigos que declaran como parece y consta por el interrogatorio de otras y que he hecho el exsamen dellos por el orden que su Señoria Yll ${ }^{\text {ma }}$ le da mando

\section{[Folio $47 \mathrm{v}$ ]}

a mi el presente notario autoricasse y cerrase esta dha ynformacion para despacharla al señor Provisor y vicario Gral del obispado Don Pedro Carmenatis Gober para que la remitiese a su señ ${ }^{a}{ } l^{\text {ma }}$ deste obispado como lo manda por su decreto para que en ello Probea lo que contenga y lo firme=

$\mathrm{BBar}^{\mathrm{me}}$ de $\mathrm{R}^{\mathrm{a}}$ Cortes [rubrica]

Ante mi

Martin Peres Destrada not ${ }^{\circ}$ [rubrica]

[Pasa al folio 54]

\section{[Folio 54 r]}

Auto. En la ciudad de Lerma en nuebe de julio de mil y seiscientos y treinta y nuebe años, el Cap ${ }^{n}$ fabian Morillo Teniente del $G^{\text {or }}$ y Just $^{a}$ mayor en ella y su jurisdicción Por su Mag ${ }^{d}$ Digo que por orden del $\mathrm{S}^{\mathrm{r}} \mathrm{G}^{\text {or }}$ desta prov ${ }^{\mathrm{a}}$ me ha embiado y manda se hagan mas diligencias sobre las muertes de los padres Gaspar Ossorio y su compañero de la Comp ${ }^{a}$ de Jesus según las advertencias que por carta me da y para que se haga despacho oy, a don Pedrillo Casique a que como $\mathrm{yn}^{\circ}, \mathrm{q}$ a recidido entre los labradillos, llame y traiga a los dos yndios que declararon en la causa a los quales dige vengan sin temor ni recelo de cosa alga , y $\mathrm{p}^{\mathrm{a}} \mathrm{q}$ conste esta diligencia lo mando asentar por auto y lo firme con dos test ${ }^{\text {os }}$ Por defecto de escrivano Fabian Morillo $t^{\circ}$ Onofre Suarez $\mathrm{t}^{\mathrm{o}} \mathrm{Ju}^{\mathrm{n}}$ Pomposso de las Higueras $=[\mathrm{al}$ margen] nombram ${ }^{\text {to }}$ de interpretes. En la ciudad de Lerma en diez y ocho días de julio de mil seiscientos y treinta y nueve años, el Cap ${ }^{\mathrm{n}}$ Fabian Morillo $\mathrm{T}^{\mathrm{e}}$ de Gov $^{\text {or }}$ y Just ${ }^{\mathrm{a}}$ mar $^{\text {or }}$ della y su juris ${ }^{\text {on }}$ Por su Magd en cumplim ${ }^{\text {to }}$ del auto de arriba se trageron algunos yndios de los labradillos y pelochocos y para los examinar es forsosso nombrar interpretes, que sepan 
la lengua de la nación de los dichos yndios y otra de la general. Y porque D. Po Cacique Pelochoco es de los dichos yndios el que habla la lengua de los dichos yndios y $\mathrm{p}^{\mathrm{a}}$ la general $\mathrm{P}^{\circ}$ Ramos [ilegible] les nombro por tal interpretes los quales lo aceptaron y juraron según forma de der ${ }^{\circ}$ de interpretar fiel y verdaderam ${ }^{\mathrm{e}} \mathrm{y}$ si assi lo hicieren les ayude Dios y al contrario se lo demande y dixeron si juran y amen, no firmaron por no saber, fírmelo yo el dho Cap ${ }^{n}$ y Just ${ }^{a} m^{\text {or }}$ con dos $t^{\text {os }}$ a falta de escriv ${ }^{\circ}$ Fabian Morillo, $t^{\circ}$ Onofre Suarez, $\mathrm{t}^{\circ} \mathrm{Juan}$ Pomposso de las Higueras $=$ [al margen] $\mathrm{t}^{\mathrm{o}} \mathrm{P}^{\circ}$ Ynobeile . En la ciudad de lerma en diez y ocho de julio de mil y seiscientos y treinta y nuebe años, yo el dho cap ${ }^{n}$ fabian Morillo $t^{e}$ de $G^{\text {or }}$ y Just ${ }^{\mathrm{a}}$ mayor Por su Mag ${ }^{\mathrm{d}}$ para averiguación de las muertes del $\mathrm{P}^{\mathrm{e}}$ Gaspar Ossorio y su compañero de la comp ${ }^{a}$ de Jesus hice traer ante mi a un yndio muchachon que por interpretación de los dhos D. Po Cacique y $\mathrm{P}^{\circ}$ Ramos dixo llamarse $\mathrm{P}^{\circ}$ ynobeile natural peluchoco de la encomienda de Marcos Cavello, del qual se tomo y recibió juram ${ }^{\text {to }}$ según forma de der ${ }^{0}$ so cargo del qual prometió decir Verd ${ }^{d}$ de lo que supiere y se le hicieron las preguntas siguientes $=$ Preguntado si este declarante fue en comp ${ }^{a}$ de los Padres Gaspar Ossorio y su comp ${ }^{o}$ por guía a la Prov ${ }^{a}$ del Chaco y asiento de los Labradillos y hasta donde llegaron y que $\mathrm{yn}^{\circ \mathrm{s}}$ descubrieron y de que naciones $=$ Dixo que no fue este declarante en comp ${ }^{\text {a }}$ de los dichos padres sino un $\mathrm{h}^{\circ}$ suyo nombrado Andres, que esta oy con los labradillos y Pelochocos a la Junta del Río Perico y que este declarante fue adelante tras de un cerro a traer una yndia madre de un yndio llamado Alonso, que estaba entre los yndios Palomos y estando este

\section{[Folio $54 \mathrm{v}$ ]}

declarante detrás del dicho cerro, llego el dicho $\mathrm{P}^{\mathrm{e}}$ Gaspar Ossorio y su compañero donde estuvieron hasta despues de Pasqua de resurrección de donde fueron al valle adentro, hacia la prova principal del Chaco, donde estuvieron algunos días, que no tiene memoria de los que serian, y habiendo descubirto una pampa al fin de un cerro grande q pasa un Rio toparon los yndios chiriguanas que venían en demanda de los yndios Palomos y aviendoles hablado los dhos $\mathrm{P}^{\mathrm{es}}$ los juntaron a todos, y repartieron las agujas y a lo que le parece abian como veinte yndios en el dicho parage, quantos días estuvieron los dhos $P^{e s}$ entre ellos, y en que se ocupaban = Dixo q solam ${ }^{\text {te }}$ estuvieron dos días los dichos Padres en el dicho parage con los dichos yndios, y bio que dieron al cacique Salapirin y Helichorin dos mantas y les mato una baca para que comiesen y en los dichos dos dias oyo este $t^{\circ}$ que los dhos $\mathrm{P}^{\mathrm{es}}$ hablaban con los dichos yndios, diciéndoles ellos estaban en lugar de Dios y $\mathrm{q}$ oyessen la palabra de Dios, lo cual unos oyan y recibían bien al principio, despues muchos dellos no querían oyrles $=$ Preguntado despues de los dos días, donde se fueron los dhos $\mathrm{P}$ es y q se hicieron los yndios chiriguanaes = Dixo que assi ceme los dichos $\mathrm{P}^{\mathrm{es}}$ como los yndios y ese $t^{\circ}$ pasaron adelante el valle y aviendo andado dos días, como vieron los $\mathrm{P}^{\mathrm{es}} \mathrm{q}$ los dichos yndios yban buenos al parecer desde aquel paraje, despacharon a un mancebo, que pretendía ser de la Comp ${ }^{a}$ llamado Sebastian, a que viniesse a esta ciudad y llevase por ella la comida de Esteco y con el vinieron dos yndios de los chiriguanas, con q los dichos $\mathrm{P}^{\mathrm{es}} \mathrm{y}$ este $\mathrm{t}^{\circ}$ pasaron adelante, $\mathrm{y}$ con los dichos yndios, a un Rio Grande y estando en este parage, y hecho noche, aquella mesma, avian bisto los dichos dos yndios, que assi fueron con el dicho Sebastian, los quales habían comunicado con los demas de su nación, como ya avian muerto al dicho Sebastian q tambien mataron a los dhos Pes, lo qual le dixo a este $t^{\circ}$ aver oydo platicar la madre del dicho Alonso q queda dicho, cuyo nombre de pila ni de su pueblo no save y que aquella noche vio este $t^{\circ}$ que los dichos yndios chiriguanaes todos juntos llegaron, a donde los dichos $\mathrm{P}^{\mathrm{es}}$ hacían noche y a su vista le quitaron las 
vestiduras, con que los dichos $\mathrm{P}^{\mathrm{es}}$ decían missa, y q nunca hablaron no quisieron quitarles las dichas vestiduras, sino que se las llevaron y otras cosas de las que llevavan los $\mathrm{P}^{\mathrm{es}}$ para los mesmos yndios, y aviendo amanecido y el sol ya fuera, embiaron los dichos padres a este $t^{0}$ a llevar a Alonso yndio que oy esta aquí, y estavan rezando, y fuele a llamar y aviendose apartado mui poco trecho vinieron los dichos chiriguanaes adonde estavan los dichos padres rezando

\section{[Folio 55 r]}

y oyo este $t^{0}$ el golpe del garrote con q dieron a los dichos Padres en este tiempo oyo este testigo la voz del Padre mas viejo Gaspar Ossorio [ilegible] hay Jesus, conq este $\mathbf{t}^{\circ}$ se alexo con los yndios Palomos, que se avian agregado de miedo, porq no les matassen, aunque siempre a vista dellos, y despues de ver muerto a los dichos $\mathrm{P}^{\mathrm{es}}$ en la algasara y huelga vio que los dhos yndios se pusieron las vestiduras, con q decían misa, q era tafetán y con esto los dhos in ${ }^{\circ s}$ llevando el despojo se fueron al Valle Rio abaxo a q los yndios palomos y algos de ellos, y Gonsalo yndio, que la ves pasada traxeron desta ciudad fueron a dond estavan los Cuerpos de los dhos $P^{e s} \mathrm{y}$ dicen los enterraron, y q este $\mathrm{t}^{\mathrm{o}}$ vio como los dichos yndios luego de aver muerto a los dhos $\mathrm{P}^{\mathrm{es}}$, anq lexos les desollavan las caveças, y q en todo el tiempo, $q$ los dichos $\mathrm{P}^{\mathrm{es}}$ comunicaron con los dichos yndios chiriguanaes, hasta llegar al Rio, donde les mataron vio este $t^{\circ}$ les hablavan cosa de Dios, $\mathrm{y}$ que fuesen $x$ pianos $=$ Preguntado $q$ los dichos yndios labradillos y palomos q allí se hallaron en la muerte de los dichos $\mathrm{P}^{\mathrm{es}} \mathrm{y}$ los que están en esas $\mathrm{p}^{\mathrm{es}}$ si se quedaron algunos, donde sucedieron las dichas muertes o se retiraron hacia el Valle de Siancas, adonde están y q cantidad de yndios abra de cada parcialidad $=$ Dixo que todos los yndios labradillos y Palomos le parece a este $t^{\circ}$ serán hasta treinta poco mas, o menos, y estos están juntos y retirados, como doce o catorce leguas de esta Ciudad q es donde se juntan los Rios de Perico y Siancas y en quanto a los yndios chiriguanaes, lo que alcanso a saber, supo no eran mucha cantidad sino pocos y estos tienen guerras, con otros yndios que están a la parte de arriba, no save que naciones. Preguntado el cuerpo del dicho Sebastian q se hizo si lo enterraron o no $=$ Dixo que publicam ${ }^{\text {te }}$ se dixo entre su nacion avian comido el dicho cuerpo, asandolo con sapallos, y que los cuerpos de los dhos Pes no los querían comer, porq decían estavan muy flacos, y no era buena carne, todo lo cual dixo ser la verdad y lo q save, vio y oyo, so cargo del juram ${ }^{\text {to }}$, q a [hecho] en q se afirmo y ratifico, aviendosele dado a entender, no supo decir su edad, pareció por su aspecto de diez y ocho o veinte años no firmo por no saver escribir, fírmelo yo el $\mathrm{Cap}^{\mathrm{n}}$ y Just ${ }^{\mathrm{a}}$ mayor, con dos $\mathrm{t}^{\mathrm{os}}$ a falta de escriv ${ }^{\mathrm{o}}$ fabian Morillo, $\mathrm{t}^{\mathrm{o}} \mathrm{P}^{\mathrm{o}}$ Pimentel, $\mathrm{t}^{\circ}$ Onofre Suares.

[al margen] $\mathrm{T}^{\circ}$ Lorenzo muchacho. En la ciudad de Lerma en diez y ocho de julio de mil y seiscientos y treinta y nuebe años, yo el dicho $\mathrm{Cap}^{\mathrm{n}} \mathrm{y} \mathrm{Just}^{\mathrm{a}}$ mayor para mas diligencias hise parecer ante mi a un muchacho, que por su aspecto tendría de trece a catorce años, poco mas o menos que por interpretación dixo llamarse Lorenzo y ser natural de Santiago del Estero encomienda del heredero de gero ${ }^{\text {mo }}$ Camargo y por dicho $\mathrm{P}^{\circ}$ Ramos

\section{[Folio $55 \mathrm{v}]$}

interprete en la lengua general $q$ habla y entiende el dicho muchacho se le recibio juram ${ }^{\text {to }}$ de forma de derecho, so cargo del qual prometió de decir verdad y se le hicieron preguntas siguientes $=$ Preguntado de donde viene este $t^{\circ} \mathrm{y}$ donde a estado $=$ dixo $q$ viene 
de donde están los yndios Palomos y labradillos reducidos y juntos donde se juntan los Ríos de Perico y Siancas $=$ Preguntado a que fue este $t^{\circ}$ a donde están los dichos yndios, y quien lo llevo = Dixo que fue Serv ${ }^{\circ}$ del $\mathrm{P}^{\mathrm{e}}$ Gaspar Ossorio, y su comp ${ }^{\circ}$ de la comp ${ }^{\text {a }}$ de Jesus al Valle del Chaco y demas valles sus circunvecinos, donde asistió en Serv ${ }^{\circ}$ de los dichos $\mathrm{P}$ ${ }^{\text {es }}$ no se a que, ni save dar raçon que tiempo a que entraron = Preguntado que se an hecho los dichos $P^{e s}=$ Dixo que los dichos $P^{\text {es }}$ fueron al dicho Valle adentro, enseñando a los yndios, que hallavan, la palabra de Dios, y llegados a un Rio Grande, q esta delante de una pampa al fin del cerro grande que fue la ultima noche, otro dia de mañana vio este $t^{\circ}$ que estando los dichos $\mathrm{P}^{\mathrm{es}}$ rezando, y el $\mathrm{P}^{\mathrm{e}} \mathrm{Gaspar}$ Ossorio passeandose y rezando, llegaron de hecho unos yndios chiriguanaes, y frentones, $y$ con garrotes dieron de garrotazos alos dichos $\mathrm{P}^{\mathrm{es}} \mathrm{y}$ a este $\mathrm{t}^{\circ}$ cogieron a este t $\mathrm{p}^{\circ} \mathrm{p}^{\mathrm{a}}$ tambien matallo, y que con esta rebuelta este $\mathrm{t}^{\circ}$ no advirtió en el fin que tuvieron los dichos yndios en matar a los dichos $\mathrm{P}^{\mathrm{es}}$, mas de $\mathrm{q} \mathrm{P}^{\mathrm{o}}$ yndio de Pelochoco, que a declarado le dixo como avia visto dar los dichos garrotazos y matar a los dichos $\mathrm{P}^{\mathrm{es}} \mathrm{y}$ que al tiempo $q$ llevavan algunos yndios a este $\mathrm{t}^{\circ}$ entre los demas, q entendían en las dichas muertes, oyo este $t^{\circ}$ una voz que decía Jesus, no se afirma qual de los dos $\mathrm{P}^{\mathrm{es}}$ era, con esto este $\mathrm{t}^{\mathrm{o}}$ volviendo los ojos a donde estavan los dichos padres, vio que degollaron al $\mathrm{P}^{\mathrm{e}}$ moço, q se llamaba $\mathrm{P}^{\mathrm{e}}$ Antonio y le quitaron la caveça y llevaron y desnudaronles sus vestiduras, lo qual vio, aunq los dichos yndios lo llevaron, quedo cerca de donde sucedió lo q a contado, y del dicho lugar vio que los perros comieron los dichos cuerpos, o alguna parte dellos, con lo qual los yndios, que avian cogido a este $t^{\circ}$ se fueron llevándosele para arriba y este $t^{\circ}$ les engaño, diciéndoles $q$ tenia una hacha, que volviesen por ella, y se la llevasen, a que volvieron, y en este tp ${ }^{\circ}$ tuvo lugar de escaparse como se escapo por aver salido a defensa un indio Alonso de los Palomos.

Preguntando que yndios abria en el susesso de las dichas muertes, y donde vinieron, y a donde alcanzaron a los dichos Padres $=$ Dixo que los yndios que allí se hallaron en las dichas muertes serian como obra de veinte la una parcialidad, y la otra de mas num ${ }^{\circ} \mathrm{q}$ no previno la cantidad y q estos muchos yndios no querían oir la palabra de Dios y qdo los dichos padres les enseñaban a rezar, hacían burla dellos y se reyan y q encontraron a los dichos $\mathrm{P}^{\text {es }}$ los dichos yndios chiriguanaes, los bellacos, adelante un poco de un Rio junto al Rio donde assistian los dychos yndios Palomos, y los chiriguanaes, q oyan la palabra de Dios, y estos enseñavan a rezar los dichos Pes

\section{[Folio 56 r]}

y lo tomaron con amor, lo q no hicieron los demas y estando en el sitio de los dichos yndios Palomos, vinieron la ultima parcialidad de chiriguanaes en busca de los dichos yndios Palomos, y allí hallaron a los dichos padres los quales les agasajaron, dándoles agujas, y algos vestidos a dos caciques que vinieron con los dichos yndios, llamados Salapirin y lehechirin y procuraron enseñarles a rezar como a dicho, y no hacían caso de ellos, sino reírse $=$

Preguntando como fue la muerte de un mancebo Sebastian, que iba en Comp ${ }^{a}$ de los dichos $\mathrm{P}^{\mathrm{es}}=$ Dixo que despues $\mathrm{q}$ se juntaron todos los dichos yndios y llegaron los dychos Padres, a un asiento de arenal, de allí enviaron al dicho Sebastian a q viniesse a esta ciudad de Salta, y llevar de comer, por esta via a la de Esteco, y lo despacharon con dos yndios de los dichos chiriguanaes, a que los yndios palomos dixeron a los $\mathrm{P}^{\mathrm{es}}$ que para $\mathrm{q}$ iban aquellos dos yndios bellacos con el dicho Sebastian, q lo matarían en el camino, y q fuesen de los mansos y no quiso el dicho Pe Ossorio, y aquella noche, del dia q de allí 
salieron, para venir hasta el valle de Siancas, los dichos yndios avian muerto al dicho sebastian, y llegaron a dar aviso a los demas yndios q estavan juntos, donde asistían los dichos padres, y aquella mañana fueron las muertes, que tiene ya dicho, y q aquella noche los dichos yndios comensaron a hacer burla de los Padres, quitándoles lo que llevaban y aun quebrando una caxa cerrada y el dia que mataron a los dichos Padres, vio que los dichos yndios cogieron el ornamento y entre todos ellos se lo partieron poniéndoselo en la algasara de sus triunfos, y q quando los dichos yndios comensaron a quitarles el hato aquella noche, los dichos padres, aunq lo vieron con amor callaron, sin decirle malas palabras, todo lo cual y lo que a dicho dixo ser verdad para el juram ${ }^{\text {to }} \mathrm{q}$ a $\mathrm{fh}^{\circ}$ en que se afirmo y ratifico, aviendosele dado a entender por el dicho interprete y es de edad a lo que parece por su aspecto de mas de trece o catorce años, y no firmo ni el dicho interprete, fírmelo yo por el dho Cap ${ }^{\mathrm{n}}$ y Just ${ }^{\mathrm{a}} \mathrm{m}^{\text {or }}$ con dos $\mathrm{t}^{\text {os }}$ por defecto de escriv ${ }^{\circ}$ fabian Morillo, $t^{\circ} \mathrm{P}^{\circ}$ Pimentel $\mathrm{T}^{\circ}$ Onofre Suares.

[al margen] to Alonso Cuchea. En la ciudad de Lerma en diez y nuebe de julio de mil y seiscientos y treinta y nuebe años yo el Cap ${ }^{n}$ y Just ${ }^{a} m^{\text {or }}$ para mas diligencias desta causa mande traer ante mi a un yndio q en su lengua y por interpretación del dicho D. Po Peluchoco, y en la general del dicho P Ramos, dixo llamarse Alonso cuchea y ser natural labradillo de la nación de los Palomos q recide en el valle de abaxo de Siancas del qual se recibió juram ${ }^{\text {to }}$ por el dicho interprete a Dios, y a una cruz según for ${ }^{\text {a }}$ de derecho so cargo del que prometió de decir verdad y se le hicieron las preg ${ }^{\text {tas }}$ sig $^{\text {tes }}=$

\section{[Folio $56 \mathrm{v}$ ]}

Preguntado si los Padres Gaspar Ossorio y su compañero de la Comp a de Jesus llegaron a su pueblo, q días estuvieron y si los enseñaban a rezar la palabra de Dios, y q yndios son estos Palomos de su nación y los labradillos = dixo que llegaron los dichos $\mathrm{P}^{\mathrm{es}}$ al asiento y cito donde este $\mathrm{t}^{\circ} \mathrm{y}$ los demas yndios y que serian según conto por sus dedos hasta veynte yndios y los juntaron y assistieron tres días y en ellos se ocuparon los dichos Padres en enseñarles la doctrina xpiana, y esto responde $=$ Preguntado despues de los tres días donde passaron los Dichos $P^{e s}$ y si este $t^{\circ}$ fue con ellos y que yndios tambien fueron $=$ Dixo que despues de los tres días los dichos $\mathrm{P}^{\mathrm{es}}$ pidieron a este $\mathrm{t}^{\mathrm{o}} \mathrm{y}$ a todos los demas yndios los llevassen la tierra adentro, hasta llegar a donde estubiesse la gruessa de los yndios y que de allí se volverían, con q este t ${ }^{\circ}$ y los demas llevaron a los dichos $P^{e s}$ la tierra dentro, y siempre les iban enseñando la doctrina christiana y aviendo caminado quatro días, encontraron a los yndios chiriguanas, q venían en demanda de los Palomos y Labradillos a los matar y allí donde los toparon, hicieron noche los dichos $\mathrm{P}^{\mathrm{es}} \mathrm{y}$ los dihos yndios y vio este test ${ }^{\circ}$ que comunicaron a los yndios, y dieron a los caciques nombrados Salapirin y Helechorin, una camiceta a cada uno y a dichos yndios dieron cuchillos y alfileres, y les enseñaron la palabra de Dios, y unos tomaron bien, y otros no quisieron haciendo burla y riéndose de los $\mathrm{P}^{\mathrm{es}}$ los quales dieron tambien a los dychos yndios una baca para que comiessen y assi icieron los dichos $\mathrm{P}^{\mathrm{es}}$ en el dicho parage donde toparon a los dichos yndios chiriguanaes, dos días y al cavo de los quales otro dia passaron los dichos yndios y los de los $\mathrm{P}^{\mathrm{es}}$ delante, a un Rio grande de donde despacharon a un mozo llamado Sebastian que volviesse atrás y saliese a esta ciudad por comida, y traxo consigo dos yndios de los dichos chiriguanaes, y que pidiesse otro $\mathrm{P}^{\mathrm{e}}$ mas, $\mathrm{y}$ con esto pasaron adelante al fin del dicho Rio grande, donde hicieron noche todos los unos y los otros yndios y los de los $\mathrm{P}^{\mathrm{es}} \mathrm{y}$ temprano de la noche volvieron los dichos dos yndios, $\mathrm{q}$ assi avian ydo con el dicho 
Sebastian, y llegados encubrieron aver muertolo, hasta casi media noche, que descubrieron unos a otros, y supo este $t^{\circ}$ como dejaron muerto atrás al dicho Sebastian, y a media noche trataron de matar a los $\mathrm{P}^{\mathrm{es}} \mathrm{y}$ para las ocasiones vio este $\mathrm{t}^{\circ}$ que los dichos yndios chiriguanaes, fueron adonde estavan los dichos $\mathrm{P}^{\mathrm{es}} \mathrm{y}$ a su vista les quitaron las vestiduras, conq decían missa y otros hatos de los susodichos, a que los dichos $\mathrm{P}^{\mathrm{es}} \sin$ acelerarse, ni reñir, los vian llevar el dicho hato y otro dia por la mañana, ya levantados los dichos $\mathrm{P}^{\mathrm{es}} \mathrm{y}$ de dia passeandose y resando en sus libros, según le mostraon un diurno pequeño y dixo eran como [ $i$ ?] en el que rezavan y a este tp ${ }^{\circ}$ vio este $t^{\circ}$ que los dichos yndios chiriguanaes, embistieron a los dichos padres y con garrotes los mataron hacien-

\section{[Folio $57 \mathrm{r}$ ]}

haciendo lo primero al $\mathrm{P}^{\mathrm{e}}$ Gaspar, el qual dixo ay Jesus y luego mataron a su compañero y vio que acabadolos de matar, los degollaron, sacando los cuerpos y dessollandolos se los llevaron solo los pellejos, quedando las caveças allí y después en sus triunfos y algarazas vio este $t^{\circ}$ que los dichos yndios se pusieron la alva y casulla, según señalo y especifico, haciendo escarnio de dichas vestiduras, y se fueron los dichos yndios hacia adelante, llevándose todo el hato de los Padres y mulas, excepto las bacas, que allí las dexaron y que al $\mathrm{tp}^{\circ}$ que los dichos yndios se ocuparon en las dichas muertes y crueldades, assi este test ${ }^{\circ}$ como el serv ${ }^{\circ}$ de los dichos Padres, y los demas yndios de su nación se apartaron porq no los matassen tambien, aunq ha vista que bien vieron todo lo que passo, y que despues que los dichos yndios delinquentes se fueron, llegaron este $\mathrm{t}^{\mathrm{t}} \mathrm{y}$ algunos yndios adonde estavan los cuerpos y los enterraron, y que este $t^{\circ}$ echo de ver, que de los dichos yndios chiriguanaes los de un ayllo o Pueblo les pesso de la muerte de los dichos Padres, riniendo a los demas q los cometiron, los quales matadores, se olgaron y festejaron las muertes y esto responde $=Y$ que temiendose de los enemigos no bolviessen para atrás el modo como enterraron a los dichos $P^{e s}$ fue cabando la tierra poca cosa, con ella y palos y ramas los enterraron y esto responde $=$ Preguntado que cantidad de yndios serian los dichos chiriguanaes, $q$ assi cometieron las dichas muertes $=$ dixo que serian como sinquenta yndios, según por los dedos contó, y esto responde $=$ Preguntado assi este $t^{\circ}$ como los demas yndios labradillos y palomos, donde están al presente = Dixo que todos están juntos y agrupados en la Junta de los ríos Siancas y Perico, como catorce leguas desta ciudad, todo lo qual dixo ser la verdad Para el juram ${ }^{\text {to }}$ que a fecha, en que se afirmo y ratifico aviednosele leído y dado a entender por los dichos interpretes, pareció por su aspecto de treinta y tres años, y no le tocaron las generales, no firmo, ni los dichos interpretes, por no saver fírmelo yo el dicho $\mathrm{Cp}^{\mathrm{n}}$ y Just ${ }^{\mathrm{a}} \mathrm{m}^{\text {or }}$ con dos test ${ }^{\mathrm{os}}$ a falta de escriv ${ }^{\circ}$ fabian Morillo $\mathrm{t}$ ${ }^{\circ} \mathrm{P}^{\circ}$ Pimentel $\mathrm{t}^{\circ}$ Onofre Suares entre renglones según las advertencias que por carta me da $=$ en esta ciudad $=[. .$.

En la ciudad de Lerma en veinte y uno de julio de mil y seiscientos y treinta y nuebe años, yo el Cap ${ }^{\mathrm{n}}$ Fabian Morillo Teniente de Gov ${ }^{\text {or }}$ y Just ${ }^{\mathrm{a}}$ mayor en ella Por su Mag ${ }^{\mathrm{d}}$ por defecto de escriv ${ }^{0}$ pub $^{0}$ y real, que no le ay

\section{[Folio $57 \mathrm{v}$ ]}

ni en su juris ${ }^{\text {on }}$ hize sacar y escribir este traslado de la información original que hice sobre las muertes de los Padres Gaspar Oosorio y su compañero de la Compañía de Jesus, según por ella parece, con lo qual se corrigio hacierto y verdadero, Siendo tes ${ }^{o s}$ a lo ver, sacar, 
corregir y concertar, Onofre Suares y Ju $\mathrm{n}^{\mathrm{n}}$ Pomposo de las Higueras, y para q valga y haga fee interpongo mi autoridad y decreto judicial y lo firme con los dichos $t^{\text {os }}$ fabian morillo $t$ ${ }^{\circ} \mathrm{Ju}^{\mathrm{n}}$ Pomposso de las Higueras t ${ }^{\circ}$ Onofre Suares.

/// Folios en blanco ///

\section{[Folio $60 \mathrm{r}$ ]}

En la ciud de lerma en nuebe de julio de mio Y seis ${ }^{\circ}$ y treinta nueve $a s^{\circ}$ el cap ${ }^{n}$ fabian morillo $\mathrm{T}^{\text {te }} \mathrm{d}$ gov $^{\text {or }} \mathrm{Y}$ jus ${ }^{\mathrm{a}}$ mayor enella y su juron ${ }^{\text {on }}$ Por su mag ${ }^{\mathrm{d}}$ - digo que por horden del $\mathrm{S}^{\mathrm{r}}$ goveror desta provincia me a embiado mandase hagan mas diligencias sobre las muertes de los padres Gaspar ossorio y su compañero de la compañía de jesus según las advertencias, que por carta me da, y para que se haga despacho oy a don Pedrillo Casique a que como $y^{\circ}$ que a residido entre los labradillos llame y traiga consigo a los dos ind ${ }^{s}$ que declararon en la causa los cuales diga vengan sin temor ni recelo de cossa alga y $\mathrm{p}^{\mathrm{a}}$ que conste esta diligencia lo $\mathrm{m}^{\mathrm{do}}$ asentar por autto $\mathrm{y}$ lo firme con $\mathrm{t}^{\mathrm{os}}$ por defecto de escriv ${ }^{\mathrm{o}}$ fabian morillo $t^{\circ}$ Onofre suares $\mathrm{t}^{\mathrm{o}} \mathrm{ju}^{\mathrm{n}}$ Pomposso de las higueras $=$ [al margen $]$ nombram ${ }^{\text {to }}$ de ynterprete. En la ciu de lerma en dies y ocho de julio de mil y seis ${ }^{\circ}$ y treinta y nuebe años el cap ${ }^{n}$ fabian morillo ten ${ }^{\text {te }}$ cap $^{n} y_{\text {jus }}{ }^{\mathrm{a}} \mathrm{m}^{\mathrm{r}}$ en ella y su juron Por su mag en cumplim ${ }^{\text {to }}$ del auto de arriva se trajeron algunos $\mathrm{yn}^{\mathrm{s}}$ de los labradillos y pelichocos y para los examinar es forzoso nombrar Ynterpretes que sepan la lengua de la nassion de los ynd ${ }^{o s} y$ otra de la general y porque don $\mathrm{P}^{\circ}$ casique Peluchoco es el que habla la lengua de los dichos yndios y para la general $p^{\circ}$ rramos cañar los nombro por tal ynterpretes los quales lo acetaron y juraron según forma de $\mathrm{dr}^{\mathrm{o}}$ de interpretar fiel y berdaderam ${ }^{\text {te }} \mathrm{y}$ si assi lo hicieren les ayude dios y al contrario se los demande, y dixeron si juran y amen no firmaron por no saber fírmelo yo el dho Cap $^{\mathrm{n}}$ y Jus ${ }^{\mathrm{a}}$ mayor con dos $\mathrm{t}^{\text {os }}$ a falta de escriv ${ }^{\mathrm{o}}$ fabian morillo $t^{\circ}$ Onofre suares $\mathrm{t}^{\mathrm{o}} \mathrm{ju}^{\mathrm{n}}$ Pomposso de las higueras. En la ciudad de lerma y diez y ocho días de julio de mil y seis ${ }^{o s}$ y treinta y nuebe yo el dho Cap ${ }^{n}$ fabian morillo ten te de goveror y just $^{\mathrm{a}}$ mayor Por su mag ${ }^{\mathrm{d}}$ para averiguass ${ }^{\mathrm{n}}$ de las muertes del $\mathrm{p}^{\mathrm{e}}$ Gaspar oss ${ }^{\mathrm{o}}$, y su compañero de la comp ${ }^{a}$ de jesus hize traer ante mi a un $y^{\circ}{ }^{\circ}$ muchachon que por interpreta ${ }^{\text {on }}$ del dho d. $\mathrm{p}^{\circ}$ cacique y el dho $\mathrm{p}^{\circ}$ rramos dixo llamarse $\mathrm{p}^{\circ}$ inobeile natural peluchoco de la encom ${ }^{\text {da }}$ de marcos cavello del qual se tomo y recibio juram ${ }^{\text {to }}$ según forma de $\mathrm{d}^{\circ}$ so cargo del cual prometió de decir la verdad de lo que supiese y se le hicieron las preguntas sigtes $^{\text {Preguntado si este declarante fue en comp }}$ Pr los padres Gaspar oss $^{\mathrm{a}} \mathrm{y}$ su compañero por guía a la provin ${ }^{a}$ del Chaco y asiento de los labradillos y hasta donde llegaron y que $\mathrm{yn}^{\text {os }}$ descubrieron y de que naciones = dixo que no fue este declarante en

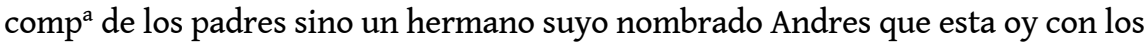
labradillos y peluchocos a la junta

\section{[Folio $60 \mathrm{v}$ ]}

del rio de Perico y que este declarante fue adelante tras de un cerro a traer a una $\mathrm{yn}^{\mathrm{a}} \mathrm{m}^{\mathrm{e}}$ de un $\mathrm{yn}^{\circ}$ llamado Alonso que estava entre los yn ${ }^{\circ s}$ Palomos y estando este declarante detrás del dho cerro llego el dho $\mathrm{p}^{\mathrm{e}} \mathrm{Gaspar}$ oss $^{\circ} \mathrm{y}$ su compañero donde estuvieron hasta despues de pascua de resurrección de donde fueron al valle adentro hacia la provina Principal del Chaco donde tuvieron algunos días que no tie memoria de los que serian y abiendo descubierto una pampa al fin de un cerro grande que passa un rrio toparon los in ${ }^{\mathrm{s}}$ chiriguanas que benian en dem ${ }^{\text {da }}$ de los yn $^{\text {s }}$ Palomos y abiendoles hablado los dhos padres 
los juntaron a todos y repartió agujas y a lo que parece abrían como beinte yn ${ }^{\text {os }}$ y esto responde.

Preguntado despues de aver topado los dhos ynd en el dho parage quantos días estuvieron los dhos $\mathrm{p}^{\mathrm{es}}$ entre ellos y en que ocupavan = dixo que solam ${ }^{\text {te }}$ estuvieron dos días los dhos Padres en el dho parage con los ynd ${ }^{o s}$ que dieron al casique Salapirin y Helichorin dos mantas y les mato una baca $\mathrm{p}^{\mathrm{a}}$ que comiesen y en los dhos días oyo este $\mathrm{t}^{\circ}$ que los dhos $\mathrm{p}^{\mathrm{es}}$ hablaban con los yndios diciéndoles que ellos estavan en lugar de Dios y que oyesen la palabra de Dios lo cual unos oyan y recibían bien al principio, despues muchos de ellos no querían oírla = preguntado después de los dos días donde se fueron los dhos padres y que se hizieron los in ${ }^{\text {os }}$ chiriguanaes = dixo que assi los dhos $\mathrm{p}^{\mathrm{es}}$ como los yn ${ }^{o s} \mathrm{y}$ este $\mathrm{t}^{\mathrm{o}}$ pasaron adelante el Valle y abiendo andado dos días como bieron los padres que los dhos $\mathrm{yn}^{\text {os }}$ yban buenos al parecer desde aquel paraje despacharon a un muchacho que pretendía ser de la compañía llamado sebastian a que biniese a esta ciu ${ }^{\mathrm{d}}$ y llevasen para ella la comida de esteco y con el vinieron dos ynd ${ }^{o s}$ de los chiriguanaes con que los dos Padres y este $t^{\circ}$ passaron adelantte y con los dhos ynd ${ }^{o s}$ a un rio grande y estando en este paraje y [separose] aquella mesma abian buelto los dhos yn ${ }^{\text {os }}$ que asi fueron con el dho Sebastian los cuales abian comunicado con los demas de su nassion como ya abian muerto a dho sebastian que tambien matasen a los dhos padres lo cual le dixo a este $t^{\circ}$

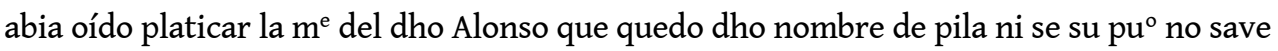
$=\mathrm{y}$ que aquella noche bio este $\mathrm{t}^{\circ}$ que los dhos ynd ${ }^{\text {os }}$ chiri

\section{[Folio 61 r]}

guanaes todos juntos llegaron a donde los dhos $\mathrm{p}^{\mathrm{es}}$ hazian noche y a su vista les quitaron las vestiduras con que los dhos $\mathrm{p}^{\mathrm{es}}$ dezian misa y que nunca hablaron ni quisieron quitarles las dichas bestiduras sino que se las llevaron y otras cosas de lo que llebaban $\mathrm{p}^{\mathrm{a}}$ los mesmos ynd ${ }^{\text {os }} \mathrm{y}$ abiendo amanesido y el sol ya fuera embiaron los dhos $\mathrm{p}^{\text {es }}$ a este $\mathrm{t}^{\mathrm{o}} \mathrm{a}$ llamar al in ${ }^{\circ}$ que oy esta aquí y estaban rezando y fuelo llamar y abiendose apartado muy poco tiempo binieron los dhos chiriguanas a donde estaban los dhos rezando y oyo este testigo el golpe del garrote con que dieron a los dhos $\mathrm{p}^{\mathrm{es}} \mathrm{y}$ en este $\mathrm{t}^{\mathrm{po}}$ oyo este $\mathrm{t}^{\mathrm{o}}$ la voz del padre mas biejo ossorio que dezia ay Jesus con que este $\mathrm{t}^{\circ}$ se alejo con los $\mathrm{yn}^{\text {os }}$ Palomos que abian agregado de miedo porque no los matassen aunque siempre a vista de ellos $y$ despues de aver muerto a los dos padres en la algazara y huelga vio que los dhos yn ${ }^{\text {os }}$ se pusieron las bestiduras con que dezian misa que era tafetan y con esto los dhos $\mathrm{yn}^{\circ}$ llebando el despoxo se fueron al valle y rrio abaxo a que los yn ${ }^{o s}$ palomos y algunos dellos y gonçalo $\mathrm{Yn}^{\circ}$ que la bes pasada trajeron a esta ciu $^{\mathrm{d}}$ fueron donde estaban los cuerpos de los dhos padres y dizen los enterraron y que este $t^{\circ}$ bio como los $\mathrm{yn}^{\text {os }}$ luego despues de aver muerto a los dhos $\mathrm{p}^{\mathrm{es}}$ auqnue de lejos les desollaban las caveças y que siempre en todo el $\mathrm{t}^{\mathrm{po}}$ que los dhos $\mathrm{p}^{\mathrm{es}}$ comunicaron con los dhos $\mathrm{yn}^{\text {os }}$ chiriguanaes y hasta llegar el rrio donde los mattaron bio este $t^{\circ}$ les hablavan cosas de dios y que fuesen cristianos.

Preguntado que dhos $\mathrm{yn}^{\text {os }}$ labradillos y palomos que assi se hallaron en la muerte de los dhos $\mathrm{p}^{\mathrm{es}} \mathrm{y}$ los que están en esas partes si que quedaron algunos donde subcedio las dhas muertes o se retiraron hazia el balle de siancas adonde estan y que cantidad de $y^{\text {os }}$ abra en cada parcialidad $=$ Dixo que todos los $\mathrm{yn}^{\text {os }}$ labradillos y palomos le parece a este $\mathrm{t}^{\circ}$ serán como hasta treinta poco mas o menos y estos estan juntos y rretirados como doze o catorze leguas de esta ciu ${ }^{\mathrm{d}}$ que es donde se juntan los rrios de perico y siancas y en cuanto a los yn ${ }^{o s}$ chiriguanas a lo que alcanso a ver supo no eran mucha cantidad sino pocos y 
estos tienen guerras con otros $\mathrm{yn}^{\text {os }}$ que están a la parte de arriva no save que nasiones = Preguntado el cuerpo del dho se

\section{[Folio $61 \mathrm{v}$ ]}

bastian que se hizo si lo enterraron = dixo que $\mathrm{Pu}^{\mathrm{ca}} \mathrm{m}^{\text {te }}$ se dixo entre su nasion abian comido al dho cuerpo assandolo con sapallos y que los cuerpos de los dhos padres no los querían comer porque dezian estaban muy flacos y no era buena carne todo lo qual dixo ser la berdad y lo que sabe bio y oyo socargo del juram ${ }^{\text {to }}$ que [ilegible] en que se afrimo y rratifico abiendosele dado a entender no supo decir su edad Parecio por su aspecto de diez y ocho a veinte $a^{o s}$ no firno Por no saver escrivir fírmelo yo el dho cap ${ }^{\text {an }} y_{j u s^{a}} m^{\text {or }}$ con dos $t^{\text {os }}$ a falta de escriv ${ }^{\circ}$ fabian morillo $t^{\circ} \mathrm{P}^{\circ}$ pimentel $t^{\circ}$ Onofre Suarez.

[Al margen] $\mathrm{T}^{\circ}$ Lorenzo muchacho. En la ciudad de lerma en dies y ocho de julio de mil y seis $^{\circ}$ y treinta y nueve años yo el dho cap ${ }^{\text {an }}$ y jus ${ }^{a}$ may ${ }^{\text {or }}$ Para mas diligencias hize parecer ante mi a un muchacho de por su aspecto tenia de treze a catorze $\mathrm{a}^{\text {os }}$ poco mas o menos que por ynterpretass ${ }^{\text {on }}$ dixo llmarse Lorenzo y ser natural de santi ${ }^{\circ}$ del estero encomienda del heredero de germo caramgo y por el dho $\mathrm{p}^{\circ}$ rramos ynterprete en la lengua general que habla y entiende el dho muchacho se le rresivio juramento según forma de derecho so cargo del qual prometio dezir verdad y se le hizieron las preguntas siguientes = Preguntado de donde biene este $t^{\circ} \mathrm{y}$ donde a estado = dixo que biene de estan los yn ${ }^{\text {os }}$ Palomos y labradillos rreduzidos y juntos donde se juntan los rrios de perico y siancas = Preguntado a que fue este $\mathrm{t}^{\mathrm{o}}$ a donde estavan los dhos $\mathrm{yn}^{\mathrm{os}} \mathrm{y}$ quien lo llevo = dixo que fue en serv ${ }^{o}$ del $p^{e}$ gaspar oss ${ }^{\circ}$ y su compañero de la comp ${ }^{a}$ de jesus al valle del chaco y demas valles sus sircunbezinos donde asistió en $\operatorname{serv}^{\circ}$ del dho $\mathrm{p}^{\mathrm{e}}$ no se acuerda ni sabe dar rrazon que tiempo a que entraron = Preguntado que se han hecho los dhos padres = dixo que los dhos $\mathrm{p}^{\mathrm{es}}$ fueron el dho balle adentro enseñando a los $\mathrm{yn}^{\mathrm{os}}$ que hallaba la palabra de dios $\mathrm{y}$ llegados a un rrio grande que esta delante de una pampa al fin del cerro grande que fue la ultima noche otro dia de mañana bio este $t^{\circ}$ que estando los dhos padres rrezando y el padre gaspar oss $^{\circ}$ Paseandose y rrezando llegaron de [...] unos $\mathrm{yn}^{\circ \mathrm{s}}$ chiriguanaes y frentones y con garrotes dieron de garrotassos a los dhos padres y a este t $^{\text {po }}$ cogieron a este $t^{o} \mathrm{p}^{\mathrm{a}}$ tambien matallo y que con esta rrebuelta este $t^{\circ}$ no advirtió en el fin que tuvieron los dhos $\mathrm{yn}^{\circ \mathrm{s}}$ en matar a los dhos padres mas de que $\mathrm{p}^{\circ} \mathrm{Yn}^{\circ}$ de pelechoco que a declarado le dixo como abia bisto dar los dhos garrotasos y matar a los dhos padres $=Y$ que al t ${ }^{\text {po }}$ que llebaban

\section{[Folio 62 r]}

algunos In $^{\text {os }}$ a este $t^{\circ}$ entre los demas que entendían en [ilegible] muertes oyo este $t^{\circ}$ una voz que dezia Jesus no se afrima qual de los dos Padres era con esto este $t^{\circ}$ bolviendo los ojos a donde estaban los dhos $\mathrm{p}^{\mathrm{es}}$ vio que degollaron al $\mathrm{p}^{\mathrm{e}}$ moço que se llamaba $\mathrm{p}^{\mathrm{e}}$ ant $^{\mathrm{o}}$ y le quitaron la cavesa y llevaron desnudandoles sus bestiduras lo qual vio porrq ${ }^{\mathrm{e}}$ aunq $^{\mathrm{e}}$ los dhos $\mathrm{yn}^{\mathrm{s}}$ lo llevaron quedo cerca de donde subcedio lo que a contado y de dho lugar bio que los perros comieron los dhos cuerpos o alguna parte dellos con lo qual los yn ${ }^{s}$ que abian cogido a este se fueron llebandole $\mathrm{p}^{\mathrm{a}}$ arriva y este $\mathrm{t}^{\mathrm{o}}$ les engaño diziendoles que tenia una hacha que bolviesen por ella y se la llebasen a que bolvieron y en ese tpo tubo lugar de escaparse como se escapo por aver salido a su defensa un $\mathrm{yn}^{\circ} \mathrm{al}^{\circ}$ de los palomos = Preguntado que in ${ }^{o s}$ abria en el subceso de las muertes y de donde binieron y a donde 
binieron y a donde alcanzaron a los dhos padres = dixo que los yn ${ }^{\text {os }}$ que asi se allaron en las dhas muertes serian como obra de veinte la una Parcialidad y la otra de mas numero que no previno la cantidad y que los muchos in ${ }^{\circ s}$ no querían oir la palabra de Dios y quando los dhos Padres les enseñavan a rezar y azian burla de ellos y reyan y q encontraron a los dhos $\mathrm{p}^{\mathrm{es}}$ los dhos in ${ }^{\text {os }}$ chiriguanaes los bellacos adelante de un poco de un rrio junto al rrio donde asistían los dhos in ${ }^{\circ s}$ palomos y los chiriguanaes que oian la palabra de Dios y estos los enseñaban a rrezar los dhos padres y lo tomaban con amor lo que no hizieron los demas y estando en el citio de los dhos in ${ }^{\circ s}$ Palomos binieron la ultima parcialidad de los chiriguanas en busca de los dhos $\mathrm{yn}^{\circ \mathrm{s}}$ palomos y allí se hallaron a los dhos padres los quales los agazaxaron dándoles aguxas y algunos vestidos a dhos casiques que binieron con los dhos yn ${ }^{\circ s}$ llamados Salapirin y Helechorin y procuraron enseñarlos a rrezar como a dho y no hazian caso dellos sino rreirse $=$ Preguntado como fue la muerte de [...] sebastian que iba en comp ${ }^{a}$ de los dhos padres = dixo que despues que se juntaron todos los dhos $\mathrm{yn}^{\mathrm{os}}$ y llegaron con los dhos padres a un asiento de arenal de allí embio al dho sebastian a que biniesse a esta ciudad de salta y llebasen de comer Por esta bia o la de esteco [...] con dos $\mathrm{yn}^{\circ \mathrm{os}}$ de los dhos chiriguanaes a que los dhos yn ${ }^{\text {os }}$ Palomos dijeron a los padres que $\mathrm{p}^{\mathrm{a}}$ que yban aquellos dos $\mathrm{yn}^{\mathrm{os}}$ bellacos con el dho sebastian

\section{[Folio $62 \mathrm{v}$ ]}

que lo matarían en el camino y que fuesen de los mas mansos y no quisoel dho $\mathrm{p}^{\mathrm{e}}$ oss $^{\mathrm{o}} \mathrm{y}$ aquella noche del dia que assi salieron Para venir hazia el valle de Siacas los dhos yn ${ }^{\circ s}$ que estaban juntos donde asistían los dhos Padres y aquella mañana fueron las muertes que tiene ya dho y que aquella noche los dhos yn ${ }^{\text {os }}$ comensaron a hazer burla de los dhos padres quitándoles lo que llebaban y aun quebrando una caxa cerrada y el dia que mataron a los dhos padres bio que los dhos $\mathrm{yn}^{\text {os }}$ cogieron el hornam ${ }^{\text {to }} \mathrm{y}$ entre todos ellos se lo partieron poniéndoselo en la algazara de sus triunfos y que quando los dhos comensaron a quitarles el hato aquella noche los dhos padres aunque lo bieron con amor callaron sin les dezir malas palabras todo lo qual y lo que a dho dixo ser la verdad Para el juram $^{\text {to }}$ que a fho en que se afirmo y ratifico abiendosele dado a entender por el dho ynterprete $Y$ es de edad a o que Parece Por su aspecto de mas de treze o catorze $a^{o s}$ y no firmo ni el dho ynterprete fírmelo yo el dho Cap ${ }^{\text {an }}$ y Jus ${ }^{\mathrm{a}}$ mayor con dos $\mathrm{t}^{\text {os }}$ Por defecto de escriv ${ }^{0}$ fabian morillo $t^{0} \mathrm{P}^{0}$ pimentel $\mathrm{t}^{\circ}$ onofre suarez.

[Al margen] $\mathrm{T}^{\circ} \mathrm{Al}^{\circ}$ cuchea. El la ciu ${ }^{\mathrm{d}}$ de lerma en diez y nueve de julio de mil y seis ${ }^{\circ} \mathrm{y}$ treinta y nuve $a^{o}$ yo el dho cap ${ }^{\text {an }} y_{\text {jus }}{ }^{\mathrm{a}} \mathrm{m}^{\text {or }}$ Para mas diligencias de esta causa mande traer ante mi a un $\mathrm{yn}^{\circ}$ que en su lengua y Por ynterpretacion del dho don $\mathrm{P}^{\circ}$ Pelechoco y en la general del dho $\mathrm{p}^{\circ}$ rramos dixo llamarse $\mathrm{al}^{\circ}$ cuchea y ser natural labradillos de la nass ${ }^{\mathrm{n}}$ de los Palomos que rresiden en el balle de debajo de siancas del qual se rrecivio juram ${ }^{\text {to }}$ por el dho ynterprete a dios y a una cruz según forma de $\mathrm{d}^{\circ}$ so cargo del qual Prometio dezir verdady se le hizieron las Preguntas siguientes $=$ Preguntado si los padres gaspar oss ${ }^{\circ}$ y su compañero de la comp ${ }^{a}$ de jesus llegaron a su pu.o que días estubieron y si los enseñaban a rrezar la palabra de dios y que $\mathrm{yn}^{\circ \mathrm{s}}$ son estos Palomos de su nass ${ }^{\mathrm{n}}$ y los labradillos = dixo que llgaron los dhos $\mathrm{p}^{\mathrm{es}}$ al asiento y citio donde este $\mathrm{t}^{\mathrm{o}} \mathrm{y}$ los demas que serian según conto Por sus dedos hasta [ilegible] yn ${ }^{\text {os }}$ y los juntaron y asistieron tres días y en ellos se ocuparon los dhos padres en enseñarles la doctrina xptiana y esto responde. 


\section{[Folio 63 r]}

Preguntado despues de los tres días donde passaron los dhos padres y si este to fue con ellos y quienes tambien fueron = dixo que despues de los dhos tres días los dos padres Pidieron a este $\mathrm{t}^{\circ} \mathrm{y}$ a todos los demas $\mathrm{yn}^{\circ \mathrm{s}}$ los llebasen la tierra dentro hasta llegar a dnde estubiesse la gruesa de los yn ${ }^{\circ s}$ y que de allí se bolverian con que este $t^{\circ}$ y los demas llevaron a los dhos padres la tierra dentro y siempre les yban enseñando la doctrina cristiana y abiendo caminado quatro días encontraron los yn.os chiriguanaes que benian en demanda de los palomos y labradillos a los matar y allí donde los [ilegible] hizieron noche los dhos padres y los dhos $\mathrm{yn}^{\circ \mathrm{os}} \mathrm{y}$ bio este $\mathrm{t}^{\circ}$ que comunicaron a los dhos $\mathrm{yn}^{\circ \mathrm{os}} \mathrm{y}$ les dio a los casiques nombrados salapirin y helochorin a una camiseta a cada uno y a otros $\mathrm{yn}^{\text {os }}$ dio cuchillos y alfileres y les enseñaron la palabra de dios que unos tomaron bien y otros no quisieron haziendo burla y rriendose de los dhos padres los les dio tambien a los dhos yn ${ }^{o s}$ una baca $\mathrm{p}^{\mathrm{a}}$ que comiessen y asistieron los dhos en el dcho paraje donde toparon a los dhos chiriguanaes dos días y al cavo de los quales otro dia Pasaron los dhos $\mathrm{yn}^{\mathrm{os}} \mathrm{y}$ los dhos padres delante a un rrio grande de donde despacharon a un moço Sebastian a que bolbiesse atrás y saliesse a esta $\mathrm{cu}^{\mathrm{d}}$ Por comida y trajo consigo dos yn ${ }^{\circ \mathrm{s}}$ de los dhos chiriguanaes y que pidiese otro padre mas y con esto Pasaron adelante al fin de este rrio grande de donde hizieron noche todos los unos y otros $\mathrm{yn}^{\mathrm{os}} \mathrm{y}$ los dhos padres $\mathrm{y}$ temprano de la noche bolbieron los dhos dos yndios que assi abian ydo con el dho sebastian y llegados yncubrieron aver muertolo hasta casi media noche que descubrieron unos a otros y supo este $t^{\circ}$ como le shabian muerto atrás al dicho sebastian y a media noche se trataron de matar a los dhos padres y para la ocasión bio este $t^{\circ}$ que los dhos yn ${ }^{o s}$ chiriguanaes fuerona a donde estaban los dichos padres y a su vista les quitaron sus bestiduras con que dezian missa y otros hatos de los susodhos a que los dhos padres sin aselerarse ni rreñir los bian llebar el dho hato y otro dia Por la mañana ya lebantados los dhos padres y de dia paseándose y rrezando en sus libros según les mostro un diurno pequeño y dixo eran como ese en el que rrezavan y a este

\section{[Folio $63 \mathrm{v}$ ]}

Tpo bio este test ${ }^{\circ}$ que los dhos $y^{\text {os }}$ chiriguanaes embistieron a los dhos padres y con garrotes los mataron hiriéndolo prim ${ }^{\circ} \mathrm{al}^{\mathrm{e}}$ gaspar oss ${ }^{\circ}$ el qual dixo ay jesus y luego mataron al compaño bio que acabadolos de matar los degollaron sacando las cabezas y llevandoselas se las llevaron solo los pellejos quedando las cabesas allí y depsues en sus triunfos y algazaras bio este $\mathrm{t}^{\circ}$ que los dhos $\mathrm{yn}^{\mathrm{os}}$ se pusieron la alva y casulla según señalo que [ilegible] haciendo escarnio de las dhas bestiduras y se fueron los dhos $\mathrm{yn}^{\circ \mathrm{s}}$ azia delante llebandose todo el hato de los padres y mulas eceto las bacas que allí las dexaron y que al tpo que los dhos yn ${ }^{\circ s}$ se ocuparon en las dhas muertes y crueldades assi este $t^{\circ}$ como el serv ${ }^{\circ}$ de los dhos padres y los demas $\mathrm{yn}^{\circ \mathrm{s}}$ de su nass ${ }^{\mathrm{n}}$ se apartaron porque no los matasen tambien a unque a bista que bien bieron todo lo que passo y que despues que los dhos $\mathrm{yn}^{\text {os }}$ delinq ${ }^{\text {tes }}$ se fueron legaron este $\mathrm{t}^{\circ} \mathrm{y}$ algunos $\mathrm{yn}^{\circ \mathrm{s}}$ a donde estaban los cuerpos $\mathrm{y}$ los enterraron que este test ${ }^{\circ}$ [a oído decir] que de los dhos chiriguanas los de un ayllo a pu - les peso de la muerte de los dhos padres rriñiendo a los demas que las cometieron los quales matadores se holgaron y festejaron las muertes y esto rresponde - y que temiendose de los enemigos no bolbiesen Para atrás el modo como enterraron a los dhos padres fue cabando la tierra poca cossa con ella y palos y rramas los enterraron y esto 
rresponde $=$ Preguntado que cantidad de $\mathrm{yn}^{\text {os }}$ serian los dhos chiriguanaes que assi cometieron las muertes $=$ Dixo que serian como $\operatorname{sinq}^{\text {ta }} \mathrm{yn}^{\text {os }}$ según Por los dedos conto y esto rresponde $=$ Preguntado aasi este $t^{\circ}$ como los demas $\mathrm{yn}^{\circ \mathrm{os}}$ labradillos y Palomos donde estan al press ${ }^{\text {te }}=$ dixo que todos estan juntos y agregados en la junta de los rrios de siancas y perico como catorce leguas de esta ciu ${ }^{\mathrm{d}}$ todo lo qual dixo ser la verdad Para el juram $^{\text {to }}$ que a fho en que se afirmo y ratifico abiendosele leído y dado a entender

\section{[Folio 64 r]}

Por los dhos ynterpretes Parecio Por su aspecto de treinta y tres $a^{\circ}{ }^{\circ}$ no le tocan las grle no firmo ni los dhos ynterpretes Por no saver fírmelo yo el dho cap ${ }^{\text {an }} \mathrm{y} \mathrm{jus}^{\mathrm{a}} \mathrm{m}^{\mathrm{or}}$ con dos tes $^{\circ}$ a falta de escriv ${ }^{\circ}$ fabian morillo $t^{\circ} \mathrm{P}^{\circ}$ Pimentel $t^{\circ}$ onofre suarez $=[. .$.$] según las$ advertencias que por carta me da $=\mathrm{a}$ esta $\operatorname{ciu}^{\mathrm{d}}=\mathrm{no}=$ padre $=\mathrm{em}^{\mathrm{do}}=$ to $=\mathrm{a}$

En la ciud de lerma en veinte y uno de jullio de mil y seis ${ }^{\text {os }}$ treinta y nuebe $a^{\text {so }}$ yo el cap ${ }^{\text {an }}$ fabian morillo $t^{\mathrm{e}}$ de gov $^{0}$ y jus ${ }^{\mathrm{a}}$ mayor en ella Por su mag ${ }^{\mathrm{d}}$. Por defecto de escriv ${ }^{\mathrm{o}} \mathrm{p}^{\mathrm{co}}$ ni real que no le ay ni en su jur ${ }^{\circ n}$ - hize sacar y escribir este traslado de la ymformass ${ }^{\mathrm{n}}$ originales que hize sobre las muertes de los padres gaspar oss ${ }^{\circ}$ y su compañero de la compañía de Jesus según [...] con lo qual se corrijio a cierto y Verd ${ }^{\circ}$ siendo $t^{\text {os }}$ a lo ver sacar corregir y concertar onofre suarez y jun $\mathrm{j}^{\mathrm{n}}$ Pomposso de las Higueras y para que haga y haga fe interpongo mi autoridad y decretos judiciales y lo firme [...]

Fabian morillo [rubrica]

$\mathrm{T}^{\circ}$ Juan Pomposo de las Higueras [rubrica]

Onofre Suarez [rubrica]

\section{NOTAS}

1. Este espacio se encontraba yuxtapuesto a un espacio jurisdiccional aún más amplio, la Provincia jesuítica del Paraguay, que comprendía los territorios del Paraguay, Río de la Plata y Tucumán. Como indicaban Xarque y Altamirano ([1687] 2008, p. 29), en lo civil y eclesiástico estos componían tres provincias, con obispo y gobernador en cada una. Los obispos dependían del Arzobispado de Chuquisaca o La Plata. En el gobierno civil y político, las tres provincias pertenecían a la ciudad de Chuquisaca para todas las apelaciones. En lo militar y gobierno superior, al Virrey del Perú en Lima. La Provincia Jesuítica del Paraguay, será la encargada de direccionar las entradas misionales al Chaco desde los Colegios creados en aquel momento.

2. AGI, Charcas, 26, R. 10, N. 90. Cartas de gobernadores. 11/11/1630, Salta. Carta de Felipe de Albornoz. Folio 1 verso - Imagen 2/4. PARES.

3. Estos pueblos de indios fueron estudiados por Sandra Sánchez y Gabriela Sica. Reducciones como las de tobas o pelichocos estuvieron ubicadas en tierras de algunos vecinos hacendados y se diferenciaron de las reducciones administradas por las órdenes religiosas por tres elementos: 1 ) los indígenas depositados en ellas lo fueron en calidad de premios por los méritos de guerra; 2) poseyeron un carácter no eclesiástico y 3) a la vez no militar. La mano de obra masculina de estas reducciones fue utilizada para el trabajo en las chacras y actividades como la provisión de leña, mientras las mujeres fueron destinadas a las faenas domésticas en haciendas y chacras (Sánchez y Sica, 1997).

4. “esta tierra - decía- tiene mejor cara de la que le ponen [...] lo que aora [sic] tengo entre manos es un pedaço de tierra muy bueno y la mejor que en las Indias se ha descubierto, muy 
regalada muy bien dispuesta vañada de Rios caudalosos". Letras annuas De La Provincia de Paraguay de los años de 1626, y 1627, de los collegios y misiones de la Comp.a de IHS. En Documentos para la Historia Argentina. Tomo XX. Iglesia. Cartas anuas de la Provincia del Paraguay, Chile y Tucumán, de la Compañía de Jesús (1615-1637). Buenos Aires. p. 260.

5. Biblioteca del Instituto Ravignani, Fondo Documental, Copias en microfilms de la Biblioteca Nacional de Brasil, Colección Pedro de Ángelis (en adelante BIR - CPD), Rollo 33, Documento 23. Informe sobre los indios ocloyas del Chaco, 1637.

6. BIR - CPD, Rollo 33, Documento 23. Informe sobre los indios ocloyas, 1637, f. $1 \mathrm{v}$.

7. ANG, Sala 9, 26-4-3, f. 46 r.

8. Esta clase de documentos han sido registrados para otros espacios como Lima, ante la beatificación de Santa Rosa (Hampe Martínez, 1998), Nueva España (Rubial García, 2001), Paraguay (Melo de Oliveira, 2010) y la vice provincia jesuítica de Chile (Blanco, 1937). Para el Tucumán colonial, sabemos que tras la muerte del misionero Antonio Solinas SJ y el clérigo secular Pedro Ortíz de Zárate en 1691 por Real Cédula al obispo de la Iglesia catedral del Tucumán se solicitaban pruebas sobre la vida y martirio de este último en 1683 (AGI, Buenos Aires, 5, L.3, f. 228v-229r. PARES), pero a la fecha no tenemos datos de la existencia efectiva de la información, por lo que el documento sobre la muerte de Osorio y sus compañeros constituye hasta ahora el único documento de esta índole para nuestro espacio.

9. AGN, Sala IX, 26-4-3, f. 57 v. En todos los casos, el resaltado me pertenece.

10. "La estructura dialógica puede ser explícita, como en la serie de preguntas y respuestas que conforman a un proceso inquisitorial, o a una transcripción de las conversaciones entre un antropólogo y su informante. Pero puede ser también implícita, como en el caso de las notas etnográficas que describen un rito, un mito o un instrumento. La esencia de lo que llamamos 'actitud antropológica', es decir la confrontación prolongada entre culturas diversas, presupone una perspectiva dialógica". En este sentido, la interacción entre inquisidor e interrogado se plantea en términos de diálogo y traducciones, en donde en algunos casos, afloran voces distintas, diferentes o contrastantes (Ginzburg, 2004, p. 221).

11. P. e., el franciscano Murillo los ubica en 1780 en las márgenes del río Bermejo, hacia el norte, junto a mataguayos, chiriguanos y otros grupos. (Morillo, [1780] 1837, p. 21).

12. BIR - CPD, Rollo 33. Carta de Don Pedro Ortíz de Zárate al gobernador, 1682.

13. BIR - CPD. Rollo 33. Verdaderas noticias del territorio, temple y cosas más principales de la provincia de Chichas y Valle de Tarija frontera de los indios chiriguanáes amigos que confinan con los indios enemigos tobas, mataguayos, frentones, chanes, mocovíes, bilelas y otras demás naciones que ocupan la Cordillera y tierras del Chaco de esta frontera. 1685. Imágenes 4-5.

14. AGN, Sala IX, 26-4-3, fs. 43 v - 44 r.

15. "aunque todas aquellas ciudades comarcanas los aclamaron por Stos y por mártires y por profetas de su Sr el obispo les hizo muy onorificas [sic] honras y mando se hiciesen por las Iglesias de su obispado hasta que la Yga les declare superiores honores". BIR - CPD. Rollo 33, documento 23. Informe sobre los indios ocloyas. F. 3r.

16. Beca CONICET PG Tipo I: "Representaciones y prácticas frente a lo santo, el cuerpo y la muerte en el imaginario misional jesuítico. Gran Chaco Gualamba, siglos XVII y XVIII”, y Beca CONICET PG Tipo II: "La santidad local como prácticas de sacralización en la frontera chaqueña. Cuerpos e imaginarios en disputa en la construcción del orden misional (Siglo XVIII)". 


\section{RESÚMENES}

El trabajo presenta la contextualización y transcripción del pedido de información sobre la muerte del jesuita Gaspar Osorio de Valderrábano y sus compañeros, levantado por orden del Obispo del Tucumán Maldonado y Saavedra entre 1639-1640 en las ciudades de Salta y Jujuy. El mismo se encuentra anexado a un expediente sobre la muerte de los padres Roque González de Santa Cruz, Alonso Rodríguez y Juan del Castillo existente en el Archivo General de la Nación y constituye un documento inédito sobre las relaciones entabladas entre los misioneros de la Compañía de Jesús y algunos grupos indígenas - pelichocos, labradillos, palomos y chiriguanosque circulaban por la confluencia de los ríos Perico y Siancas en la frontera jujeña en la primera mitad del siglo XVII. El informe, que reúne testimonios de indígenas reducidos de la encomienda de Marcos Cabello, constituye una fuente que contribuye al conocimiento de estos grupos, algunos prácticamente desconocidos por la historiografía de la región, las relaciones entabladas con los misioneros en instancias de fricción interétnica y las respuestas que estos grupos plantearon ante estas circunstancias en un espacio geoetnico variado.

The paper presents the context and transcript of the request of information on the death of the Jesuit Gaspar Osorio Valderrábano and his companions, composed by order of the Bishop of Tucuman, Maldonado y Saavedra, between 1639-1640, in the cities of Salta and Jujuy. This is an appendix to a file in the General Archive of the Nation regarding the death of the priests Roque Gonzalez de Santa Cruz, Alonso Rodriguez and Juan del Castillo. It is an unpublished document that refers to the relationship between the missionaries of the Society of Jesus and some indigenous groups-Pelichocos, Labradillos, Palomos and Chiriguanos-who used to move around near the confluence of the rivers Perico and Siancas, in the border of Jujuy, during the first half of the seventeenth century. The report, which compiles testimonies of "reduced" Indians from Marcos Cabello's encomiendas, is a source that contributes to the knowledge of these groupssome practically unknown to the historiography of the region-, the relationship established with the missionaries in a situation of ethnic friction, and the solutions reached by these groups under such circumstances in a varied "geo-ethnic" space.

ÍNDICE

Keywords: Pelichocos, Labradillos, Palomos, Chiriguanos, Conversion, Chaco

\section{AUTOR}

\section{RENÉ OSVALDO GERES}

CEPIHA, Universidad Nacional de Salta. Becario de posgrado del CONICET, Argentina. Correo electrónico: osvaldo_geres@hotmail.com. Integra el proyecto CIUNSa 1893/3. 